ARTICLE

https://doi.org/10.1038/s41467-021-22543-z

\title{
Mutations inhibiting KDM4B drive ALT activation in ATRX-mutated glioblastomas
}

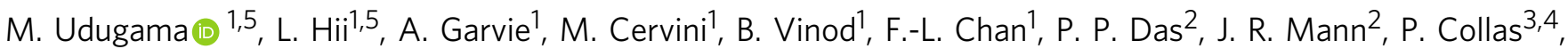 \\ H. P. J. Voon (10) ${ }^{1 凶} \&$ L. H. Wong (1) ${ }^{1 凶}$
}

Alternative Lengthening of Telomeres (ALT) is a telomere maintenance pathway utilised in $15 \%$ of cancers. ALT cancers are strongly associated with inactivating mutations in ATRX; yet loss of ATRX alone is insufficient to trigger ALT, suggesting that additional cooperating factors are involved. We identify $\mathrm{H} 3.3^{\mathrm{G} 34 \mathrm{R}}$ and IDH1/2 mutations as two such factors in ATRX-mutated glioblastomas. Both mutations are capable of inactivating histone demethylases, and we identify KDM4B as the key demethylase inactivated in ALT. Mouse embryonic stem cells inactivated for ATRX, TP53, TERT and KDM4B (KDM4B knockout or H3.3G34R) show characteristic features of ALT. Conversely, KDM4B over-expression in ALT cancer cells abrogates ALT-associated features. In this work, we demonstrate that inactivation of KDM4B, through $\mathrm{H} 3.3 \mathrm{G} 34 \mathrm{R}$ or IDH1/2 mutations, acts in tandem with ATRX mutations to promote ALT in glioblastomas.

\footnotetext{
${ }^{1}$ Department of Biochemistry and Molecular Biology, Biomedicine Discovery Institute, Monash University, Clayton, Victoria, Australia. ${ }^{2}$ Department of Anatomy and Developmental Biology, Biomedicine Discovery Institute, Monash University, Clayton, Victoria, Australia. ${ }^{3}$ Department of Molecular Medicine, Institute of Basic Medical Sciences, Faculty of Medicine, University of Oslo, Oslo, Norway. ${ }^{4}$ Department of Immunology and Transfusion Medicine, Oslo University Hospital, Oslo, Norway. ${ }^{5}$ These authors contributed equally: M. Udugama, L. Hii. ${ }^{凶}$ email: joanna.voon@monash.edu; lee.wong@monash.edu
} 
T elomeres are stretches of repetitive DNA that cap and protect the ends of linear chromosomes. In vertebrates, telomeres are comprised of a tandemly repeated hexamer (TTAGGG) several kilobases long, which is recognised and bound by Shelterin ${ }^{1,2}$, a multimeric protein complex that prevents the natural ends of chromosomes from being recognised as DNA breaks. These DNA repeats buffer the genome from the 'end-replication problem' where incomplete replication of the lagging DNA strand leads to gradual shortening of chromosomes with each round of DNA replication. The loss of telomeric sequence with successive rounds of cell division eventually leads to critically short telomeres which cannot bind Shelterin. This results in a loss of telomere integrity and imposes a natural biological limit on cellular proliferation. Highly proliferative cells must activate a telomere maintenance mechanism. During early embryogenesis, this is facilitated by high-level expression of telomerase, a reverse transcriptase that uses an RNA template to elongate telomeres ${ }^{3}$. Telomerase is downregulated during late stages of development and is often only reactivated in cancers. Much like stem cells, one hallmark of cancers is the capacity for unlimited cell division. This oncogenic process must be supported by a telomere maintenance programme, either through reactivation of telomerase or activation of the Alternative Lengthening of Telomeres (ALT) pathway ${ }^{4,5}$.

The ALT pathway is utilised in $15 \%$ of cancers $^{6-9}$, with high prevalence $(>50 \%)$ in gliomas, pancreatic neuroendocrine tumours, osteosarcomas and soft-tissue sarcomas $7,8,10,11$. The maintenance of ALT is dependent on a host of DNA repair proteins ${ }^{12,13}$ sequestered with telomeres in specialised nuclear compartments known as ALT-associated PML bodies $(\mathrm{APBs})^{5,14,15}$. However, the initiation and early stages of ALT remains an enigmatic process and only one protein, ATRX ( $\alpha$ thalassaemia/mental retardation syndrome-X-linked), has been consistently linked to ALT activation. ATRX is a chromatin remodeller that acts in complex with DAXX to deposit the histone variant $\mathrm{H} 3.3$ and form a heterochromatin structure at telomeres ${ }^{16-22}$. Inactivating mutations in ATRX are highly correlated with ALT, implicating ATRX as a suppressor of the ALT mechanism ${ }^{6-9}$. However, neither knockdown nor knockout of ATRX is sufficient to activate $\mathrm{ALT}^{9,23}$, suggesting that additional cooperating factors are necessary. To identify these factors, we searched public cancer genome databases for mutations that segregated with ATRX inactivation in glioblastoma multiforme (GBM), where ALT is particularly prevalent ${ }^{6,10}$. We found two frequent mutations within this cohort; one in histone $\mathrm{H} 3.3$ (H3.3 ${ }^{\mathrm{G} 34 \mathrm{R}}$; glycine to arginine substitution) and one in isocitrate dehydrogenase (IDH1/2). We re-created the $\mathrm{H} 3.3^{\mathrm{G} 34 \mathrm{R}}$ and ATRX mutations in mouse ES cells that lack telomerase (TERT) and TP53, and show in this model system that H3.3 ${ }^{\mathrm{G} 34 \mathrm{R}}$ cooperates with ATRX inactivation to induce ALT. We further show that both $\mathrm{H} 3.3^{\mathrm{G} 34 \mathrm{R}}$ and $\mathrm{IDH} 1^{\mathrm{R} 132 \mathrm{H}}$ promote ALT through the inhibition of KDM4B, a histone K9/K36 demethylase. Our results demonstrate that $\mathrm{H} 3.3^{\mathrm{G} 34 \mathrm{R}}$ and $\mathrm{IDH} 1 / 2$ are parallel mutations that promote ALT by inhibiting KDM4B.

\section{Results}

H3.3 $334 \mathrm{R}$ collaborates with ATRX inactivation to induce ALT. ALT is common in GBM in younger patient cohorts where it is

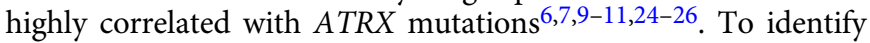
additional factors which may promote ALT, we explored the cBioPortal database $\mathrm{s}^{27,28}$ for mutations that overlapped with ATRX-mutant GBM in patients aged 30 years and younger6,11. We found that the majority of ATRX-mutated GBMs have additional mutations in the checkpoint regulator TP53, and either H3F3A (H3.3) or IDH1 (Isocitrate Dehydrogenase 1) (Fig. 1a,
Supplementary Table S1). The TP53 mutations were common across the ATRX-mutant GBMs, while H3.3 and IDH1 mutations were mutually exclusive. Three mutations were found in $H 3 F 3 A$ (K27M, G34R and G34V), with G34R (H3.3 $\left.{ }^{\mathrm{G} 34 R}\right)$ being the most common $^{6}$, while IDH1 mutations were almost exclusively $\mathrm{IDH}^{\mathrm{R} 132 \mathrm{H}}$ (substitution of Arginine 132 with a Histidine). We, therefore, hypothesised that $\mathrm{H} 3.3^{\mathrm{G} 34 \mathrm{R}}$ and $\mathrm{IDH} 1^{\mathrm{R} 132 \mathrm{H}}$ are factors that collaborate with ATRX to activate ALT. To test this, we created mouse embryonic stem (ES) cell lines with homozygous knockouts of three genes known to be involved in ALT: Atrx (-/Y), the checkpoint regulator TP53 (-/-), and telomerase Tert $(-/-)$ (APT-tKO), with and without a heterozygous $\mathrm{H} 3.3^{\mathrm{G} 3} 4 \mathrm{R}$ substitution (H3.3G34R APT-tKO) (Supplementary Fig. 1). In the absence of telomerase activity, both the APT-tKO and H3.3 ${ }^{\mathrm{G} 34 \mathrm{R}}$ APT-tKO cell lines showed gradual erosion of telomeric DNA over time at a similar rate (Fig. 1b, c). Telomeres in APTtKO cells were virtually undetectable by telomere DNA FISH analysis after 12 months in culture, and these cells reached a growth crisis after 16 months (Supplementary Fig. S2a, b). The H3.3 ${ }^{\mathrm{G} 34 \mathrm{R}} \mathrm{APT}-\mathrm{tKO}$ cells also reached a telomere crisis after 12 months in culture but recovered both cell growth and telomere length within 2 months (Fig. 1c, Supplementary Fig. S2a, b). As these cells are telomerase negative, the recovery of $\mathrm{H} 3.3^{\mathrm{G} 34 \mathrm{R}} \mathrm{APT}$ tKO cells was highly suggestive of ALT activation.

In support of ALT activation in our cell models, we detected ALT-associated hallmarks in H3.3G34RAPT-tKO cells including telomeric C-circle DNA (Fig. 1d) ${ }^{29}$, sister chromatin exchange (Fig. 1e, Supplementary Fig. S2c; examples of TSCE are shown), and large ALT-associated promyelocytic leukaemia (PML) bodies (APBs) (Fig. 1f, g). The telomere recovery in $\mathrm{H} 3.3^{\mathrm{G} 34 \mathrm{R}} \mathrm{APT}-\mathrm{tKO}$ cells was also accompanied by the binding of TERF1, a Shelterin complex subunit (Fig. 1f, g). In contrast, TERF1 was undetectable in APT-tKO by 14 months, reflecting the loss of telomere repeats, and PML bodies remained as small, speckled and disorganised entities (Fig. 1f). These findings in $\mathrm{H} 3.3^{\mathrm{G} 34 \mathrm{R}} \mathrm{APT}-\mathrm{tKO}$ cells $\left(\mathrm{H} 3.3^{\mathrm{G} 34 \mathrm{R}} \mathrm{APT}-\mathrm{tKO} \# 1\right.$ line) were reproducible across an independent cell line (H3.3 ${ }^{\mathrm{G} 34 \mathrm{R}} \mathrm{APT}-\mathrm{tKO}$ \#2; Supplementary Figs. S3 and S4). We note that all four mutations are required for activation of ALT, as single and double H3.3 ${ }^{\mathrm{G} 34 \mathrm{R}} 30$ and $A \operatorname{trx} x^{-/ Y} 31$ mutants, showed stable maintenance of telomere length over a period of 9 months although the $\mathrm{H} 3.3^{\mathrm{G} 34 \mathrm{R}} A \operatorname{trx}{ }^{-/ Y}$ double mutant showed reduced telomere length (Supplementary Fig. S5). Together, these results suggest that $\mathrm{H} 3.3^{\mathrm{G} 34 \mathrm{R}}$ is a cooperating mutation which acts in tandem with ATRX-KO to promote ALT.

KDM4B is a key regulator of telomeric chromatin. We have previously shown that $\mathrm{H} 3.3^{\mathrm{G} 34 \mathrm{R}}$ inhibits the KDM4 histone $\mathrm{K} 9$ / K36 demethylases, leading to changes in $\mathrm{H} 3 \mathrm{~K} 9 \mathrm{me} 3$ and H3K36me3 across the genome ${ }^{30}$. We, therefore, speculated that H3.3G34R may facilitate ALT by inhibiting KDM4 function at telomeres. There are three major KDM4 enzymes in mammals; KDM4 - A, -B and -C, which all catalyse removal of H3K9 and H3K36 di- and trimethyl modifications ${ }^{32}$. Protein immunoprecipitation showed all three KDM4 proteins can interact with $\mathrm{H} 3.3$ (Fig. 2a) and chromatin immunoprecipitation-sequencing (ChIPseq) data ${ }^{33,34}$ identified KDM4B as the most prominent demethylase at telomeres (Fig. 2b). KDM4B is also enriched at IAPLTRs, relative to KDM4 A/C, while KDM4 A/C are preferentially enriched at GC-rich tandem repeats relative to KDM4B (Supplementary Fig. S6).

Previous studies have shown that KDM4A controls chromatin accessibility and alters replication timing of a late-replicating heterochromatic satellite region by demethylating $\mathrm{H} 3 \mathrm{~K} 9 \mathrm{me} 3$ and antagonising the binding of heterochromatin protein 1 (HP1 $)^{35,36}$. Based on these findings, we hypothesised that 
a

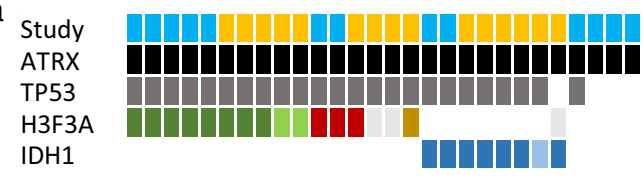

$\mathrm{IDH} 1$ b

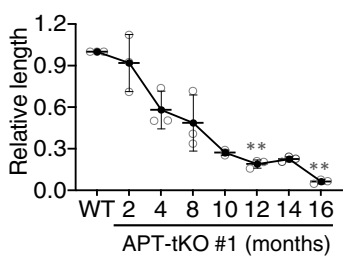

C

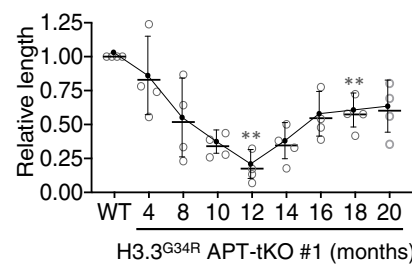

d
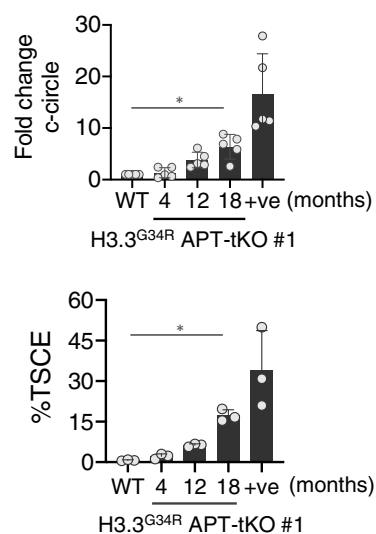
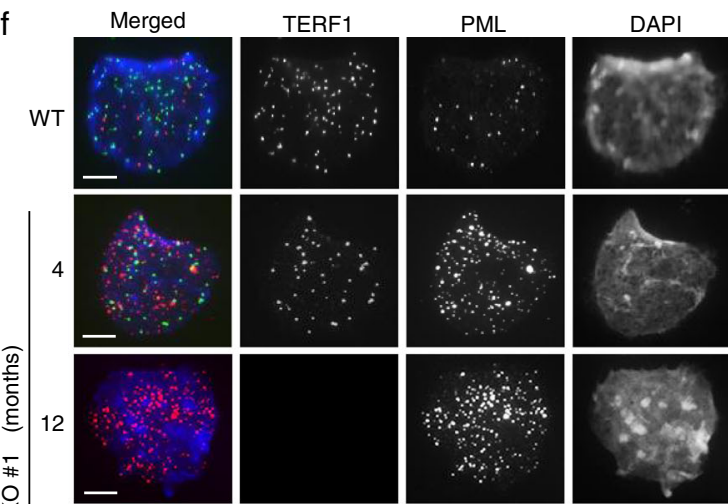

14
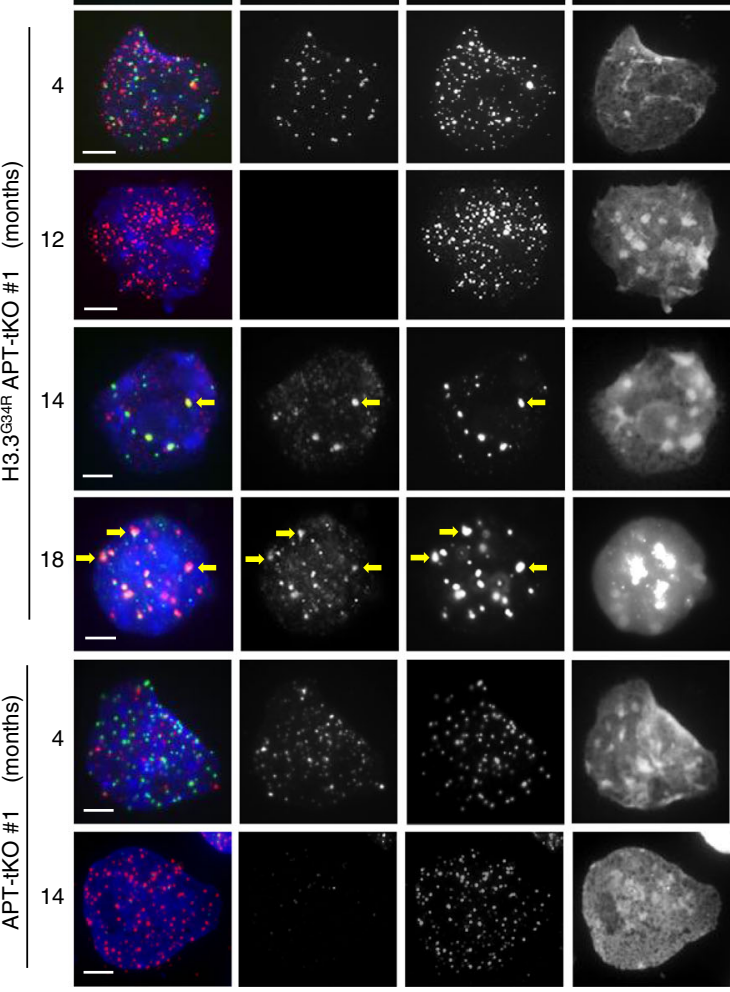

g

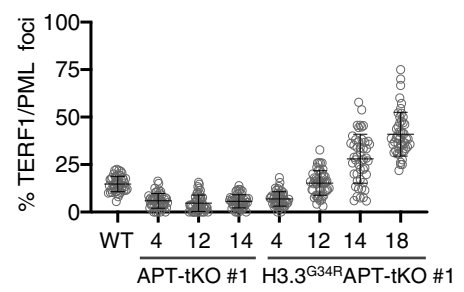

Fig. 1 H3.3 ${ }^{\text {G34R }}$ promotes ALT in APT-tKO mouse ES cells. a Glioblastoma tumours from patients aged 30 years and younger with ATRX, H3.3, IDH1 and TP53 mutations. b, c Telomere length analyses of APT-tKO \#1 and H3.3G34RAPT-tKO \#1 ES cells, in relative to WT (wildtype) ES cells ( $n=3$ independent experiments). d Detection of telomeric C-circle in H3.3G34RAPT-tKO cells ( $n=5$ independent experiments). e Detection of T-SCE in H3.3G34RAPT-tKO cells ( $n=3$ independent experiments). Human U2OS osteosarcoma ALT cell line was included as a positive ( + ve) control. $\mathbf{f}, \mathbf{g}$ Immunostaining of APBs in APT-tKO cells and H3.3G34RAPT-tKO, shown by co-staining of TERF1 (green; diluted at 1/500) and PML (red; diluted at 1/800) (arrows). Scale bars: $5 \mu$ m; representative images from at least $n=3$ independent experiments. Percentages of co-localised TERF1 and PML foci in H3.3G34RAPT-tKO\#1 cells are shown in $\mathbf{g}$. For each cell line, $>1500$ telomeric foci were counted ( $n=3$ independent experiments; indicated by TERF1 staining). Percentage of co-localised TERF1/PML foci are determined as percentages of telomeric foci that co-stained with PML over the total number of telomeric foci counted. $\mathbf{b}, \mathbf{c}, \mathbf{d}, \mathbf{e}, \mathbf{g}$ Data are presented as mean values \pm SD. ${ }^{\star}$ indicates $p<0.05$ and ${ }^{*}$ indicates $p<0.005$, Student's $t$-test with two-tailed distribution. Source data are provided with this paper.

KDM4B regulates accessibility of telomeric heterochromatin to facilitate DNA replication. Consistent with this, KDM4B is enriched at telomeres in G1/early S-phase (Fig. 2c). We created a $K d m 4 b$ homozygous knockout $\left(K d m 4 b^{-/}\right)$mouse ES cell line (Supplementary Fig. S7a, b) and found increased total H3K9me3 and H3K36me3 in these cells (Fig. 2d). ChIP-qPCR of H3K9me3, ATRX, H3.3, total H3 and HP1a showed increased levels of all heterochromatin-associated proteins at telomeres in $\mathrm{Kdm}_{4} \mathrm{~b}^{-/-}$ cells, suggestive of chromatin compaction and heterochromatinisation (Fig. 2e). This altered chromatin profile did not affect the maintenance of telomere length (Supplementary Fig. S7c) but led to increased replication stress at telomeres as detected by BrdU incorporation and a DNA damage marker $(\gamma \mathrm{H} 2 \mathrm{AX})$ in two independent $K d m 4 b^{-/-}$clones. $K d m 4 b^{-/-}$cells showed decreased BrdU incorporation (Fig. 2f) as well as increased levels of $\gamma \mathrm{H} 2 \mathrm{AX}$ at the telomeres (Fig. $2 \mathrm{~g}, \mathrm{~h}$ ). Treatment with low concentrations of a DNA replication inhibitor, aphidicolin $(\mathrm{APH})$, exacerbated this phenotype and led to substantially increased $\gamma \mathrm{H} 2 \mathrm{AX}$ at telomeres and across entire chromosomes (Fig. 2g, h, Supplementary Fig. S7d), while wild-type (WT) cells showed only modest differences. Of interest, $K d m 4 b^{-/-}$cells also showed increased levels $\gamma \mathrm{H} 2 \mathrm{AX}$ at DAPI dense regions which are 
a

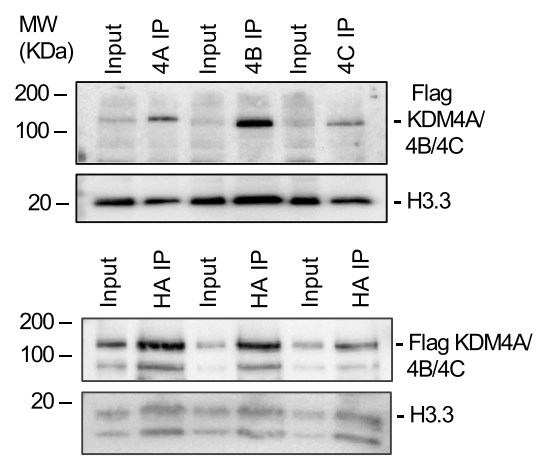

e
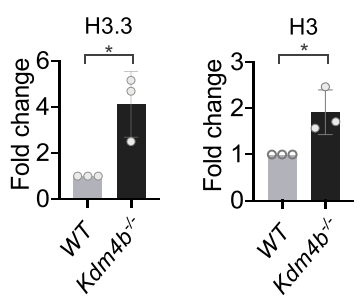

$\mathrm{H} 3 \mathrm{~K} 9 \mathrm{me} / \mathrm{H} 3$

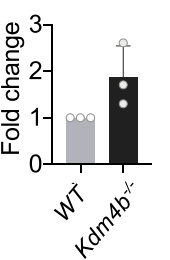

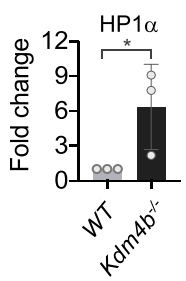

f

TEL-BRDU

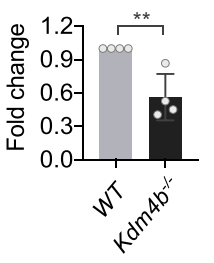

GAPDH-BRDU

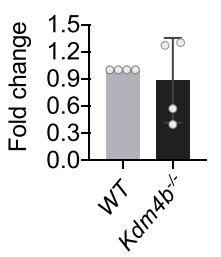

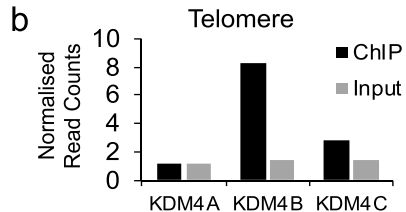
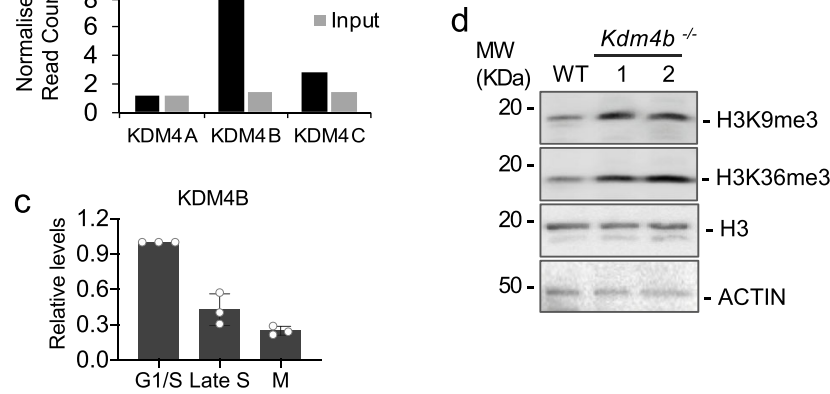

g
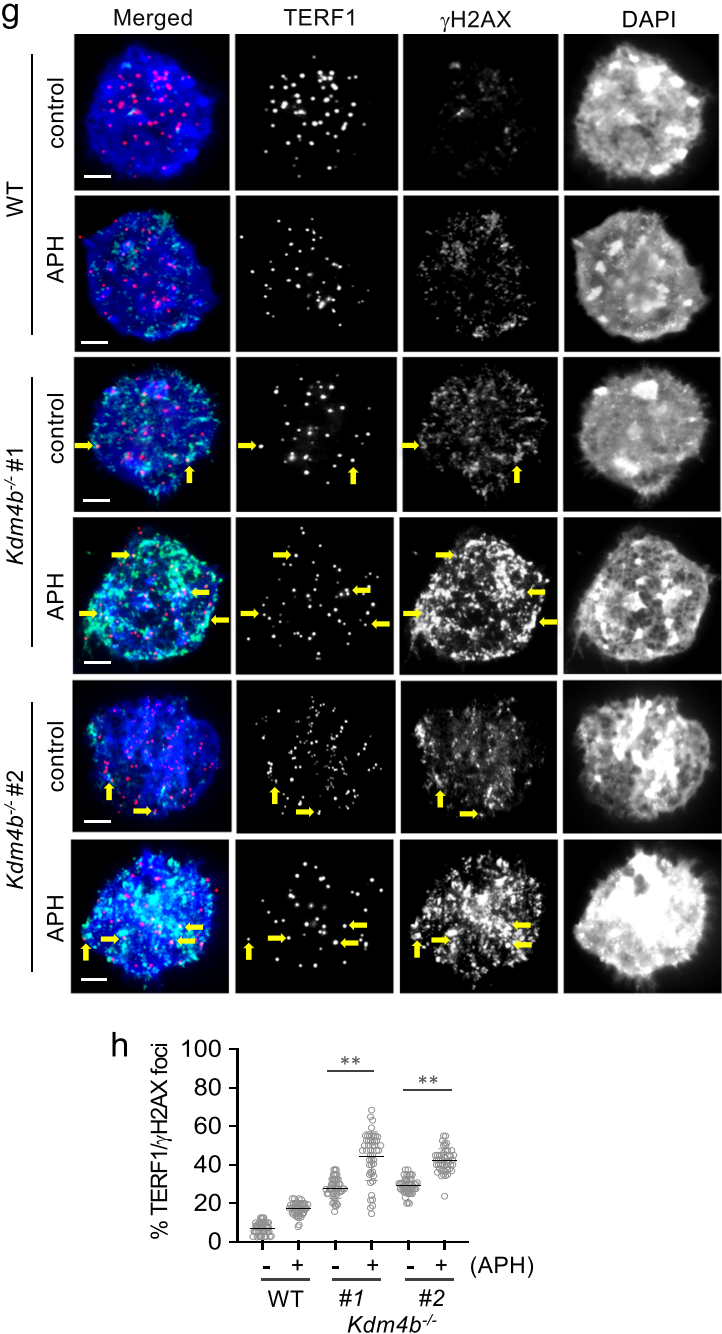

Fig. 2 KDM4B-/- mouse ES cells show replication stress. a Protein immunoprecipitation with an anti-Flag antibody in ES cells expressing HA-H3.3 and either Flag-tagged KDM4A, KDM4B or KDM4C, followed by western blot analysis with an anti-HA antibody. b ChIP-sequencing analysis of KDM4 - A $^{34}$, $-B^{33}$ and $-C^{33}$ with input sequencing. Data shows reads which aligned to telomeres, normalised for total read counts showing KDM $4 B$ binding to telomeres. c ChIP-qPCR analysis of KDM4B at telomeres in cell cycle-synchronised cells ( $n=3$ independent experiments). d Western blot analyses of WT and KDM4B cells using antibodies against H3K9me3, H3K36me3, H3 and ACTIN. e ChIP-qPCR analyses of H3.3, total H3, H3K9me3, ATRX, HP1 $\alpha$. Level of H3K9me3 was normalised to total H3 levels $(\mathrm{H} 3 \mathrm{~K} 9 \mathrm{me} 3 / \mathrm{H} 3)(n=3$ independent experiments). $\mathbf{f}$ ChIP-qPCR analyses of BrdU incorporation at telomeres and Gapdh promoter in WT and $K d m 4 b^{-/-}$cells ( $n=4$ independent experiments). $\mathbf{g}, \mathbf{h}$ Immunofluorescence analyses of TERF1 (red; diluted at $\left.1 / 500\right)$ and $\gamma \mathrm{H} 2 \mathrm{AX}$ (green; diluted at 1/1500) in WT and $\mathrm{Kdm} 4 \mathrm{~b}^{-/-}$cells with and without $1 \mathrm{mM} \mathrm{APH}$ treatment for $5 \mathrm{~h}$. Arrows indicate presence of DNA damage $(\gamma \mathrm{H} 2 \mathrm{AX})$ at telomeres (TERF1). Scale bars: $5 \mu \mathrm{m}$. Percentages of co-localised TERF1 and $\gamma \mathrm{H} 2 \mathrm{AX}$ foci in two independent $K d m 4 b^{-/-}$cell lines $\left(K d m 4 b^{-} /-\right.$ $\# 1$ and \#2) are shown in $\mathbf{h}$. For each cell line, $>1500$ telomeric or TERF1 foci were counted ( $n=4$ independent experiments). Percentage of co-localised TERF1/ $\gamma \mathrm{H} 2 \mathrm{AX}$ foci are determined as percentages of telomeric foci that co-stained with $\gamma \mathrm{H} 2 \mathrm{AX}$ over the total number of telomeric foci counted. $\mathbf{c}, \mathbf{e}, \mathbf{f}, \mathbf{h}$ Data are presented as mean values \pm SD. *indicates $p<0.05$ and ${ }^{*}$ indicates $p<0.005$, Student's $t$-test with two-tailed distribution. $\mathbf{a}$, $\mathbf{d}, \mathbf{g}$ Representative images and blots from at least $n=3$ independent experiments. Source data are provided with this paper. 
likely to be pericentric heterochromatin domains (Fig. 2g). Collectively, these results in our ES cell models show that KDM4B regulates chromatin accessibility, with its loss of function resulting in replication stress and damage at telomeres.

Loss of ATRX and KDM4B function is required for ALT. ATRX has been proposed to resolve stalled replication forks through incorporation of $\mathrm{H} 3.3$, and much like the $K d m 4 b^{-1-}$ cells, loss of ATRX leads to increased DNA replication stress at telomeres ${ }^{37}$. It is possible that ATRX and KDM4B act in concert to maintain telomeres, such that ATRX can partially compensate for the loss of KDM4B, and vice versa. This would support the idea that $\mathrm{H} 3.3^{\mathrm{G} 34 \mathrm{R}}$ promotes ALT through inhibition of KDM4B, as the $\mathrm{H} 3.3^{\mathrm{G} 34 \mathrm{R}} / \mathrm{ATRX}$-mutated GBMs would suffer a two-hit mutation in this pathway.

To test if $\mathrm{H} 3.3^{\mathrm{G}} 34 \mathrm{R}$ is activating ALT through inhibition of KDM4B, we knocked out KDM4B directly in APT-tKO (Kdm4b-l-APT-tKO) cell lines that had been cultured for 10 months (Supplementary Fig. S8). In order to determine if KDM4B and ATRX acted in concert, we also knocked out $K d m 4 b$

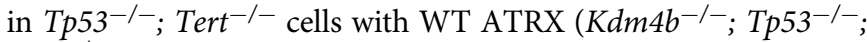
$\mathrm{Tert}^{-1-}$ ) (Supplementary Fig. S8). Both lines showed a gradual loss of telomeric DNA over time, with a more pronounced loss in the $K d m 4 b^{-/-}$APT-tKO cells (Fig. 3a, b, Supplementary Fig. S9).

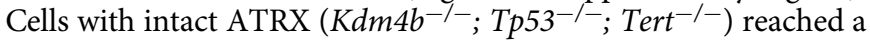
growth crisis after a further 6 months in culture, and telomeres were undetectable by either FISH or TERF1 immunostaining (Fig. 3c, Supplementary Fig. S9a, b). In contrast, telomeres in $K d m 4 b^{-1-}$ APT-tKO cells shortened rapidly over a 4-month period, followed by recovery of telomere length and cell growth by 6 months (Fig. 3b, Supplementary Fig. S9a, b). Much like the H3.3 ${ }^{\mathrm{G} 34 \mathrm{R}} \mathrm{APT}$-tKO cells, the $K d m 4 b^{-1-}$ APT-tKO cells showed all the hallmarks of ALT, namely recovery of telomere length, restored TERF1 binding and telomeres encapsulated by APBs (Fig. 3c, d). These findings in $K d m 4 b^{-1-}$ APT-tKO cells $\left(K d m 4 b^{-1}\right.$-APT-tKO \#1) were reproducible in an independent cell line ( $K d m 4 b^{-/}$APT-tKO \#2; Supplementary Fig. S10). Taken together, these results demonstrate that a combinatorial loss of KDM4B and ATRX is required to activate ALT, and support the idea that $\mathrm{H} 3.3^{\mathrm{G} 34 \mathrm{R}}$ acts through inhibition of KDM4B.

Unlike the H3.3 ${ }^{\mathrm{G} 34 \mathrm{R}} \mathrm{APT}-\mathrm{tKO}$ and $K d m 4 b^{-/-}$APT-tKO, the APT-tKO cells with functional KDM4B were unable to activate ALT (Fig. 1b) and failed to form the large APBs at telomeres which are required for ALT (Fig. 1f, g). Despite the presence of PML bodies, APT-tKO cells failed to form large APBs with telomeric co-localisation and the telomere signals were below the level of detection, whereas H3.3 ${ }^{\mathrm{G} 34 \mathrm{R}} \mathrm{APT}-\mathrm{tKO}$ and $K d m 4 b^{-1-}$ APT-tKO (Fig. 1f, g, 3c, d, Supplementary Fig. S4a) form APBs following ALT activation. PML bodies are phaseseparated liquid compartments stabilised by multivalent interactions between proteins and nucleic acids ${ }^{38}$ and function in heterochromatin remodelling ${ }^{39-41}$. The heterochromatin protein, HP1 $\alpha$, is known to drive phase separation ${ }^{42,43}$ and HP1a binds the H3K9me3 residue ${ }^{44}$ which is demethylated by KDM4B. It is therefore possible that the continued activity of KDM4B at APTtKO telomeres prevents the formation of phase-separated APBs by reducing HP1a recruitment through the removal of H3K9me3. Consistent with this, we found that APT-tKO cells had elevated KDM4B binding at telomeres and reduced $\mathrm{H} 3 \mathrm{~K} 9 \mathrm{me} 3$ (Fig. 3e). To test if removal of KDM4B was sufficient to nucleate the formation of APBs, we knocked out $K d m 4 b$ in late-passage (12 months continuous culture) APT-tKO cells (APT-tKO ${ }^{12 \mathrm{~m}}$ ) with telomeres in prolonged crisis (Supplementary Fig. S11a, b). The acute removal of KDM4B in APT-tKO ${ }^{12 \mathrm{~m}}\left(\mathrm{APT}^{\mathrm{A}} \mathrm{tKO}^{12 \mathrm{~m}}\right.$ /
$K d m 4 b^{-/-}$) led to increased H3K9me3 and HP1 $\alpha$ at telomeres (Fig. 3e, f, g), accompanied by formation of APBs and restoration of TERF1 binding (Supplementary Fig. S11c, d). It is clear that the loss of ATRX is an absolute requirement for ALT, yet, paradoxically, loss of ATRX alone (APT-tKO) creates a chromatin environment that precludes the formation of APBs at telomeres. ALT telomere maintenance requires a threshold level of heterochromatin ${ }^{45-47}$ which in this case was achieved through inactivation of KDM4B. Our results suggest that in ATRX-mutated ALT cancers, loss of KDM4B results in an increase of $\mathrm{H} 3 \mathrm{~K} 9 \mathrm{me} 3$ - and $\mathrm{HP} 1 \alpha$-containing heterochromatin to a level that can sustain and stabilise the formation of APBs.

KDM4B activity inhibits APB formation and the ALT pathway. If loss of KDM4B activity is critical for initiating ALT, then expression of KDM4B would likely be detrimental to established ALT cell lines. We tested this by overexpression of KDM4B in two human ALT cell lines (U2OS and GM847), alongside two nonALT counterparts (B143, HEK293). In ALT-positive cells, U2OS (Fig. 4a-d) and GM847 (Supplementary Fig. S12a-d), ectopic expression of KDM4B led to prominent binding of KDM4B at telomeres (Fig. 4a, b; Supplementary Fig. S12a, b) accompanied by loss of APBs and high levels of DNA damage $(\gamma \mathrm{H} 2 \mathrm{AX})$ (Fig. $4 \mathrm{c}, \mathrm{d}$; Supplementary Fig. S12c, d). In contrast, ectopic expression of KDM4B in non-ALT counterparts, B143 (Fig. 4a-d) and HEK293 (Supplementary Fig. 12a-d) showed only low levels of KDM4B binding (Fig. 4a, b; Supplementary Fig. 12a, b) with no significant increase of $\gamma \mathrm{H} 2 \mathrm{AX}$ (Fig. 4c, d; Supplementary Fig. S12c, d) at the telomeres. These results demonstrate that expression of KDM4B is sufficient to disrupt APBs and induce telomeric damage in an established ALT cell model.

In addition to $\mathrm{H} 3.3^{\mathrm{G} 34 \mathrm{R}}$, ATRX-mutated ALT-positive GBMs are also frequently mutated in IDH1 $\left(\mathrm{IDH} 1^{\mathrm{R} 132 \mathrm{H}}\right)$, and these two mutations are mutually exclusive (Fig. 1a). The IDH1 ${ }^{\mathrm{R} 132 \mathrm{H}}$ mutation produces a 2-hydroxyglutarate oncogenic metabolite which inhibits 2-oxo-glutarate dependent di-oxygenases, including the KDM4 family of enzymes ${ }^{48}$. It is therefore possible that, like the $\mathrm{H} 3.3^{\mathrm{G} 34 \mathrm{R}}$ mutations, the $\mathrm{IDH1}{ }^{\mathrm{R} 132 \mathrm{H}}$ mutation also promotes ALT through inhibition of KDM4B. We created mouse ES cells with an IDH1 ${ }^{\mathrm{R} 132 \mathrm{H}}$ mutation (Supplementary Fig. S13a) and observed many similarities with $K d m 4 b^{-/-}$cells, supporting the idea that $\mathrm{IDH} 1^{\mathrm{R} 132 \mathrm{H}}$ inhibits $\mathrm{KDM} 4 \mathrm{~B}$. The $\mathrm{IDH} 1^{\mathrm{R} 132 \mathrm{H}}$ mutants (clones \#1 and \#2) showed increased levels of total H3K9me3 and H3K36me3 (Fig. 5a) with no significant change in telomere length (Supplementary Fig. S13b, c). The IDH1 ${ }^{\mathrm{R} 132 \mathrm{H}}$ mutants also showed a telomere stress phenotype very similar to $K d m 4 b^{-/-}$cells including decreased BrdU incorporation (Fig. 5b), increased $\gamma \mathrm{H} 2 \mathrm{AX}$ at telomeres, and increased sensitivity to APH treatment (Fig. 5c, d Supplementary Fig. S13d). In addition, much like the $K d m 4 b^{-l-}$ mutant, the IDH1 $1^{\mathrm{R} 132 \mathrm{H}}$ mutants also showed increased staining of $\gamma \mathrm{H} 2 \mathrm{AX}$ at DAPI dense regions which are likely the pericentric heterochromatin. These results show that IDH1 $1^{\mathrm{R} 132 \mathrm{H}}$ induces a telomere replication stress phenotype similar to that seen in $K d m 4 b^{-/-}$cells. This strongly suggests that both $\mathrm{H} 3.3^{\mathrm{G} 34 \mathrm{R}}$ and $\mathrm{IDH} 1^{\mathrm{R} 132 \mathrm{H}}$ can inhibit KDM4B activity, and that inhibition of KDM4B is a common component in promoting ALT in ATRX-mutated cancers.

\section{Discussion}

ALT tumours are frequently inactivated for ATRX, yet inherited mutations in ATRX (underlying the ATR-X syndrome) do not have appreciable effects on cancer predisposition. The loss of ATRX is therefore necessary but not sufficient for ALT, and additional events are required for ALT activation. By searching public cancer genome databases, we identified $\mathrm{H} 3.3^{\mathrm{G} 34 \mathrm{R}}$ and $\mathrm{IDH} 1^{\mathrm{R} 132 \mathrm{H}}$ as potential 
a

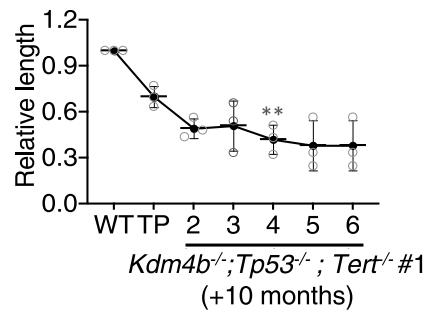

b

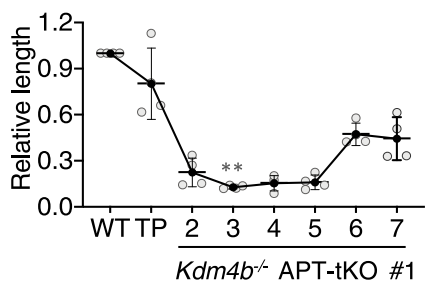

(+10 months)
C

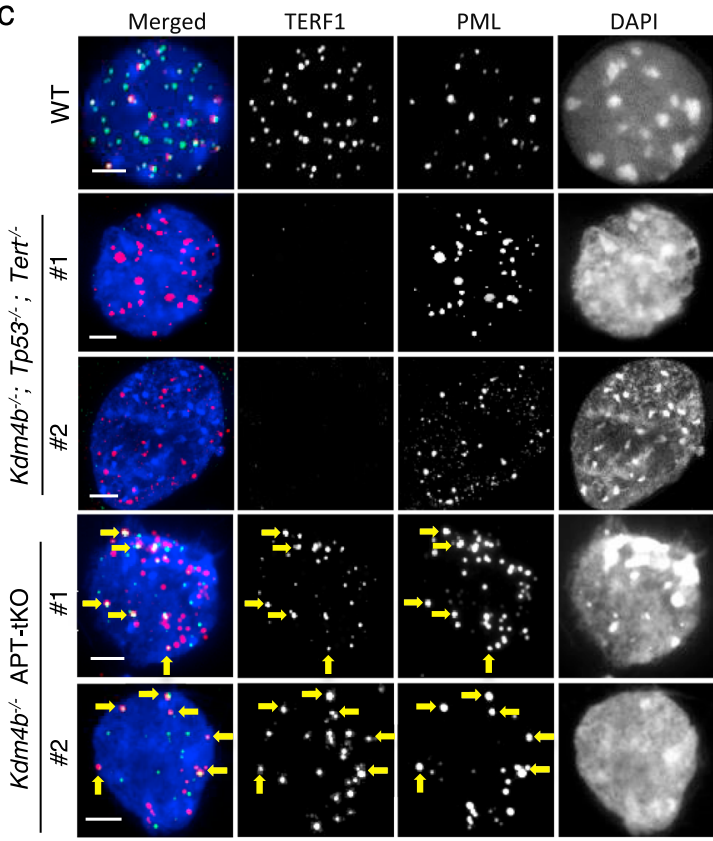

f
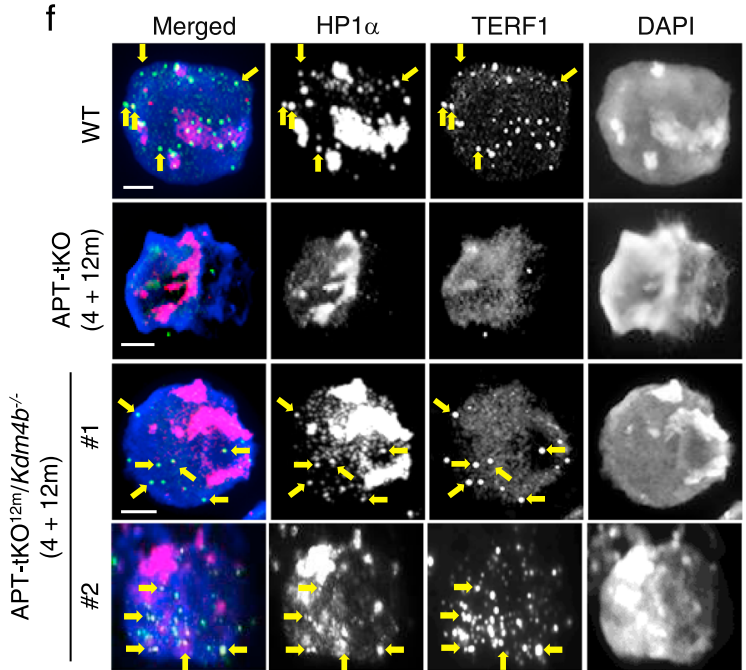

$\mathrm{H} 3 \mathrm{~K} 9 \mathrm{me} / \mathrm{H} 3$
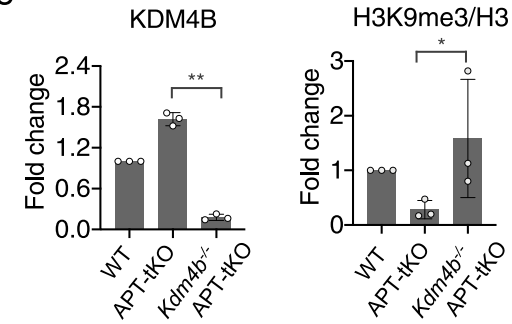

H3

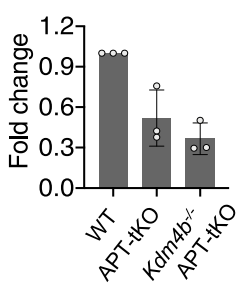

d
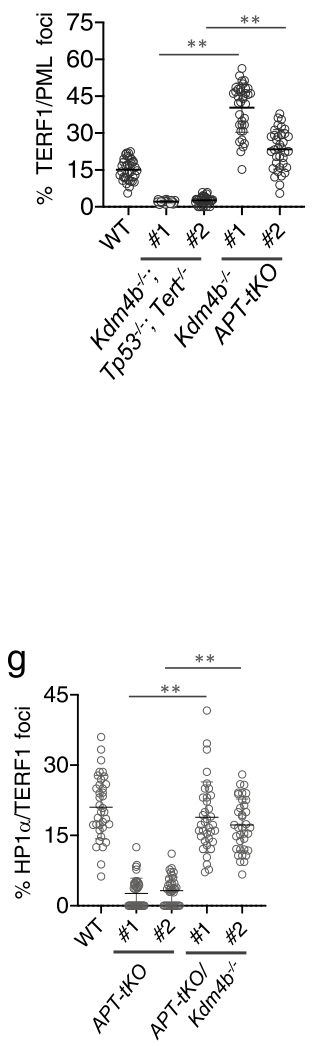

Fig. 3 The inhibition of KDM4B by H3.3 ${ }^{\mathbf{G} 34 \mathbf{R}}$ contributes to ALT activation. $\mathbf{a}$, b Telomere length analyses of $K d m 4 b^{-/-} ; T p 53^{-/-} ; T e r t^{-/-}$and $K d m 4 b^{-/-A P T-t K O}$ cells over a 6-month period following knockout of $K d m 4 b$ in Tp53-/-; Tert ${ }^{-/-}$(TP) and APT-tKO cells ( $n=3$ independent experiments). c, d Immunostaining of APBs in $K d m 4 b^{-/-} ;$Tp53 $3^{-/-} ; T_{e r t}{ }^{-/-}$and $K d m 4 b^{-/-}$APT-tKO cells, shown by co-staining of TERF1 (green)

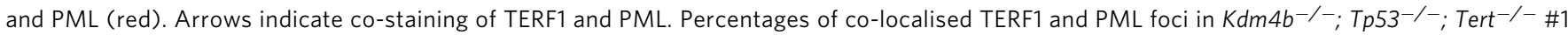
and $K d m 4 b^{-/-}$APT-tKO \#1 are shown in $\mathbf{d}$ ( $n=5$ independent experiments; $>1200$ foci counted for each line). e ChIP-PCR analyses of KDM4B, H3K9me3 and H3 in WT, APT-tKO and APT-tKO ${ }^{12 m} \mathrm{Kdm}_{4} \mathrm{~b}^{-/-}$cells. Level of H3K9me3 was normalised to total H3 levels $(\mathrm{H} 3 \mathrm{~K} 9 \mathrm{me} 3 / \mathrm{H} 3)(n=3$ independent experiments). f, g Immunostaining of TERF1 (green; diluted at 1/500) and HP1 $\alpha$ (red; diluted at 1/500) in WT, APT-tKO ${ }^{12 \mathrm{~m}}$ and APTtKO ${ }^{12 \mathrm{~m}} \mathrm{Kdm} 4 b^{-/-}$cells, 4 months in culture following $K d m 4 b$ knockout. Arrows indicate co-staining of TERF1 and HP1 $\alpha$. Percentages of co-localised TERF1 and HP1 $\alpha$ foci in APT-tKO ${ }^{12 m}$, APT-tKO ${ }^{12 m} K_{d m} 4 b^{-/-\# 1 ~ a n d ~ \# 2 ~ a r e ~ s h o w n ~ i n ~} \mathbf{g}$. For each cell line, $>1500$ telomeric or TERF1 foci were counted ( $n=3$ independent experiments). Percentage of co-localised TERF1/HP1 $\alpha$ foci are determined as percentages of telomeric foci that costained with HP1 $\alpha$ over the total number of telomeric foci counted. $\mathbf{a}, \mathbf{b}, \mathbf{d}, \mathbf{e}, \mathbf{g}$ Data are presented as mean values $\pm \mathrm{SD}$. ${ }^{\star}$ indicates $p<0.05$ and ${ }^{\star \star}$ indicates $p<0.005$, Student's $t$-test with two-tailed distribution. c, f Scale bars: $5 \mu$ m; representative images from at least $n=3$ independent experiments. Source data are provided with this paper.

mutations which may collaborate with ATRX to induce ALT in glioblastomas affecting younger age groups. By creating primary cell models of ALT using mouse ES cells, we discovered that combined mutations of $\mathrm{H} 3.3^{\mathrm{G} 34 \mathrm{R}}$ and ATRX are required to activate ALT, and $\mathrm{H} 3.3^{\mathrm{G} 34 \mathrm{R}}$ promotes ALT by inhibiting the KDM4B histone demethylase at telomeres. We demonstrate in mouse ES cells that $\mathrm{H} 3.3^{\mathrm{G} 34 \mathrm{R}}$ and $\mathrm{Kdm} 4 \mathrm{~b}^{-/-}$are functionally equivalent in promoting $\mathrm{ALT}$, and it is highly likely that $\mathrm{IDH} 1^{\mathrm{R} 132 \mathrm{H}}$ acts in the same pathway. Furthermore, ectopic expression of KDM4B induces telomere damage in ALT-positive cells. Our data suggest that loss of KDM4B is required for ALT, and provides the first example of ALT activation in a primary cell model by manipulating four defined factors: inactivation of telomerase, TP53 checkpoint, ATRX, and KDM4B (either H3.3 $334 \mathrm{R}$ or $K d m 4 b^{-/-}$).

The maintenance of telomeres in ALT requires many DNA repair proteins ${ }^{12,13}$ and this complex process is dependent on the 
a
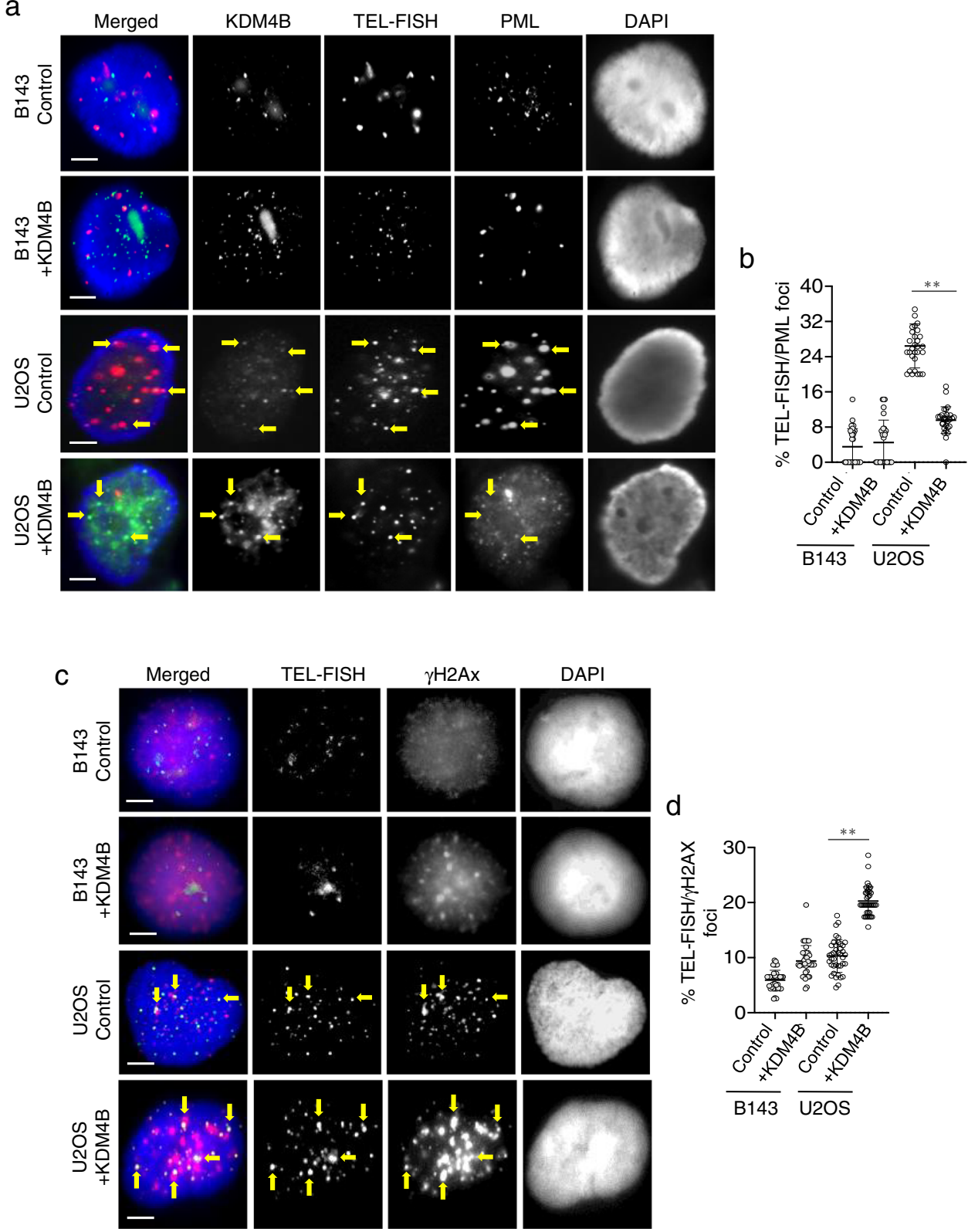

Fig. 4 KDM4B activity inhibits the ALT pathway. Immunostaining of KDM4B (green), PML (red) and TEL-FISH (cyan) in control or KDM4B transfected B143 and U2OS cells. Arrows show KDM4B at telomeres (a). Percentages of co-localised TEL-FISH and PML foci in H3.3G34RAPT-tKO\#1 cells are shown in b $(n=3$ independent experiments; $>500$ foci counted). Immunostaining of $\gamma \mathrm{H} 2 \mathrm{AX}$ (red; diluted at 1/500) and TEL-FISH (green) analyses in B143 and $\mathrm{U} 2 \mathrm{OS}$ cells with and without overexpression of KDM4B (+KDM4B). Arrows show $\gamma-\mathrm{H} 2 \mathrm{AX}$ at telomeres (c). Percentages of co-localised TEL-FISH and $\gamma \mathrm{H} 2 \mathrm{AX}$ foci are shown in d. For each cell line, $>1500$ telomeric or TEL-FISH telomeric foci were counted ( $n=4$ independent experiments). Percentage of co-localised TEL-FISH/ $\gamma \mathrm{H} 2 \mathrm{AX}$ foci are determined as percentages of telomeric foci that co-stained with $\gamma \mathrm{H} 2 \mathrm{AX}$ over the total number of telomeric foci counted. b, d Data are presented as mean values \pm SD. ${ }^{\star \star}$ indicates $p<0.005$, Student's $t$-test with two-tailed distribution. a, c Scale bars: $5 \mu$ m; representative images from at least $n=3$ independent experiments. Source data are provided with this paper.

formation of phase-separated APBs at ALT telomeres ${ }^{5,14,15}$. APBs are one of the defining hallmarks of ALT and removal of APBs in ALT cancer lines results in telomere shortening and damage ${ }^{49,50}$. In addition, the coalescence of APB condensates may promote telomere clustering/recombination which is required for telomere DNA synthesis in $\mathrm{ALT}^{14,51,52}$. As telomeres are heterochromatic, formation of APBs is likely dependent on HP1a which is known to be a strong driver of phase separation ${ }^{42,43}$. The binding of $\mathrm{HP} 1 \alpha$ is dependent on $\mathrm{H} 3 \mathrm{~K} 9 \mathrm{me} 3^{44}$, the modification demethylated by KDM4B. In normal cells, KDM4B most likely plays a role in controlling chromatin accessibility by antagonising $\mathrm{H} 3 \mathrm{~K} 9 \mathrm{me} 3$ / HP1a at telomeres ${ }^{36}$. This appears to be particularly important for facilitating DNA replication, as knockout $\left(K d m 4 b^{-/-}\right)$or inhibition (IDH $1^{\mathrm{R} 132 \mathrm{H}}$ ) of KDM4B leads to increased replication stress and DNA damage at telomeres. However, in ALT cells the continued demethylase activity of KDM4B at telomeres could become a liability in the absence of ATRX-mediated heterochromatin assembly, as further losses of $\mathrm{H} 3 \mathrm{~K} 9 \mathrm{me} 3 / \mathrm{HP} 1$ a could create a chromatin environment incompatible with formation of APBs. Supporting this, ectopic expression of KDM4B in 
a

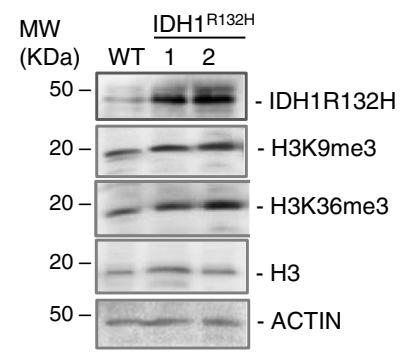

b

TEL-BRDU

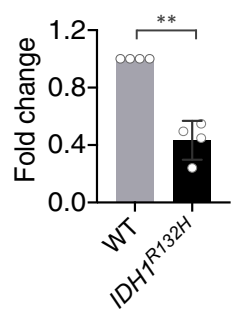

GAPDH-BRDU
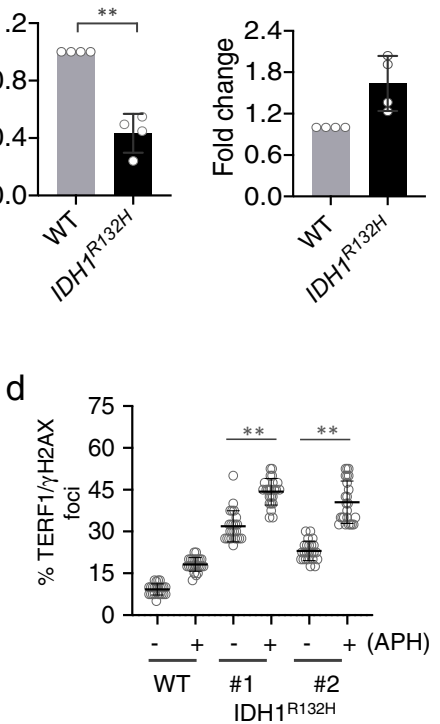

C
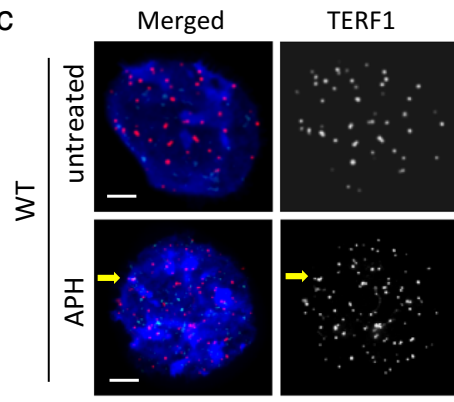

$\gamma \mathrm{H} 2 \mathrm{AX}$
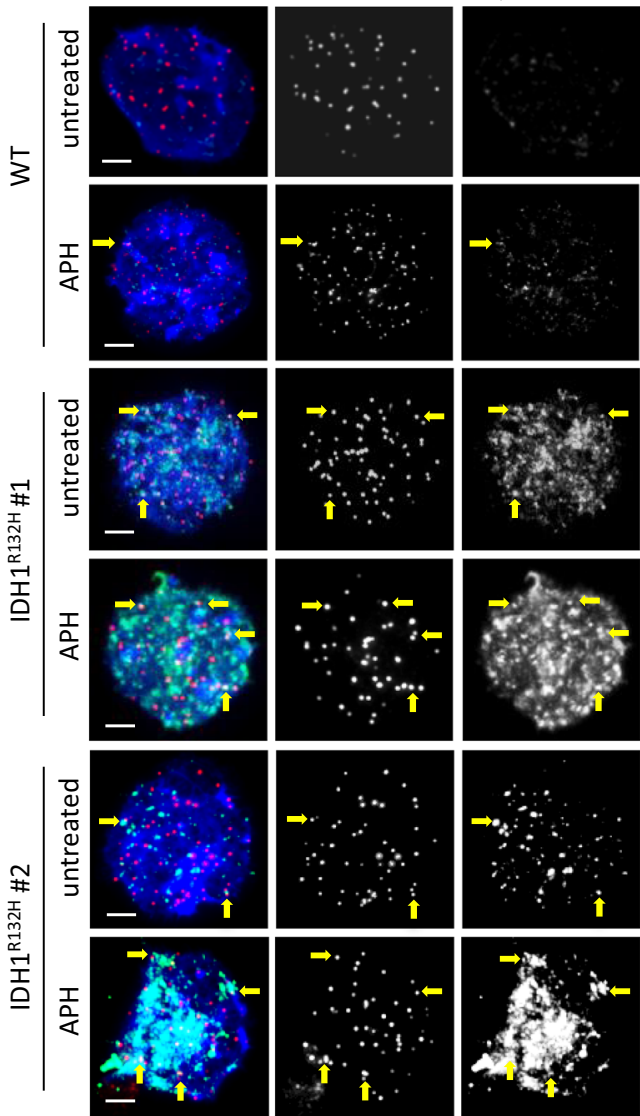
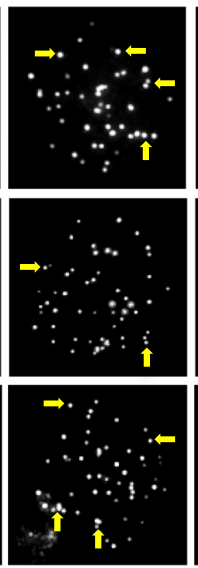

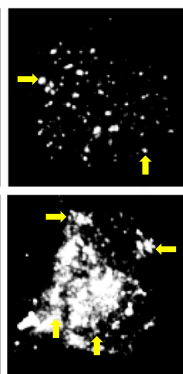

DAPI
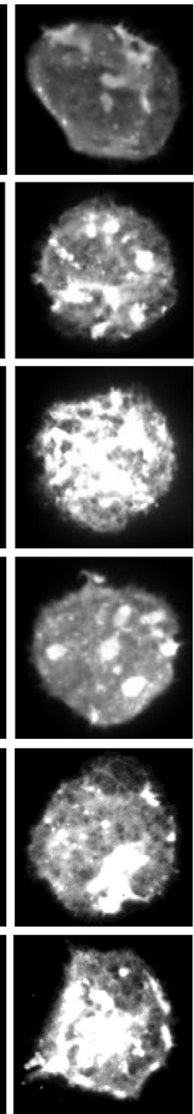

Fig. 5 IDH1 ${ }^{\text {R132H }}$ mouse ES cells show replication stress. a Western blot analyses of WT and IDH1 ${ }^{R 132 H}$ ES cells using antibodies against IDH1R132H, H3K9me3, H3, H3K36me3 and ACTIN. b IP-qPCR analyses of BrdU incorporation at telomeres and Gapdh promoter in WT and IDH1R132H ES cells ( $n=3$ independent experiments). Immunofluorescence analyses of TERF1 (red; diluted at 1/500) and $\gamma \mathrm{H} 2 \mathrm{AX}$ (green; diluted at 1/1500) in WT and IDH1 R132H ES cells with and without $1 \mathrm{mM} \mathrm{APH}$ treatment for $5 \mathrm{~h}$. Arrows indicate co-staining of $\gamma \mathrm{H} 2 \mathrm{AX}$ and TERF1 (c). Percentages of co-localised TERF1 and $\gamma \mathrm{H} 2 \mathrm{AX}$ foci are shown in d. For each cell line, $>1500$ telomeric or TERF1 foci were counted ( $n=4$ independent experiments). Scale bars: $5 \mu \mathrm{m}$. Percentage of colocalised TERF1/ $\gamma \mathrm{H} 2 \mathrm{AX}$ foci are determined as percentages of telomeric foci that co-stained with $\gamma \mathrm{H} 2 \mathrm{AX}$ over the total number of telomeric foci counted. b, $\mathbf{d}$ Data are presented as mean values $\pm \mathrm{SD}$. ${ }^{* \star} p<0.005$, Student's $t$-test with two-tailed distribution. $\mathbf{a}, \mathbf{c}$ Representative images and blots from at least $n=3$ independent experiments. Source data are provided with this paper.

established ALT cancer lines leads to dissociation of APBs and increased DNA damage at telomeres. Conversely, inhibition $\left(\mathrm{H} 3.3^{\mathrm{G} 34 \mathrm{R}}, \mathrm{IDH} 1^{\mathrm{R} 132 \mathrm{H}}\right)$ or knockout $\left(\mathrm{Kdm}_{4} \mathrm{~b}^{-/-}\right)$of KDM4B leads to increased $\mathrm{H} 3 \mathrm{~K} 9 \mathrm{me} 3$ and HP1a at telomeres and facilitates APB formation in our mutant cell lines.

However, we note a quiescent period occurring in between the telomere crisis, and the nucleation of APBs and telomere lengthening in our cell models. This period likely represents the initiation phase of ALT which may include events such as the recruitment of factors, and execution of processes that stabilise and prepare telomeres for lengthening. To date, most investigations have been conducted on ALT cell lines derived from advanced cancers when the process of ALT is well underway. As a result, very little is known about the initiation and early phases of ALT. As we have now established a cell model which reliably undergoes ALT, it should now be possible to investigate these early stages in more detail. In addition, we cannot exclude the possibility that additional factors may be involved in activating ALT during telomere crisis. For example, loss of telomerase may be directly required for ALT activation. While previous studies in human cancer cell lines have shown that expression of telomerase (TERT) does not abolish ALT activity ${ }^{53}$, inhibition of telomerase in a mouse cancer model can induce $\mathrm{ALT}^{54}$. Furthermore, a number of studies have reported the non-canonical role of telomerase in telomeric chromatin maintenance and resolution of DNA damage, in addition to its function in telomere DNA elongation ${ }^{55,56}$. It remains to be clarified how telomerase loss may contribute to ALT, and if it suppresses ALT by removing telomeric intermediates that arise during telomeric replication stress or crisis.

We have identified KDM4B as a novel factor involved in ALT in ATRX-mutated glioblastomas, and KDM4B can be inactivated either through $\mathrm{H} 3.3^{\mathrm{G} 34 \mathrm{R}}$ or $\mathrm{IDH} 1^{\mathrm{R} 132 \mathrm{H}}$. Intriguingly, $A T R X$ mutations and ALT are also common in paragangliomas and pheochromocytomas 57,58 , and these tumours have frequent mutations in Krebs cycle genes, such as fumarate hydratase $(F H)$ and succinate dehydrogenase $(S D H x)$, leading to an accumulation of fumarate and succinate $32,58,59$. Much like the IDH1/2 mutations, fumarate and succinate are competitive inhibitors of $\alpha-K G$ dependent dioxygenases, including $\mathrm{KDM}_{4} \mathrm{~B}^{32,59}$. It will be interesting to investigate if $\mathrm{FH}$ and $\mathrm{SDH} x$ mutations also inhibit KDM4B and act as cooperating factors to promote ALT in ATRXmutated cancers. In conclusion, we provide evidence that inactivation of KDM4B is a critical factor in activating the ALT 
pathway in ATRX-mutated glioblastomas. The clinical significance of KDM4B inactivation in other ATRX-mutated ALT cancers requires further studies.

\section{Methods}

Gene mutation analysis. Information regarding ATRX, TP53, H3F3A and IDH1/2 alterations in human GBM tumours (Supplementary Table S1) was obtained from The Cancer Genome Atlas (TCGA) database, an open-access database publicly available at http://www.cbioportal.org 6,11,26-28,60,61.

Cell culture. Mouse ES cells and derived cell lines were cultured in Dulbecco's modified Eagle's medium supplemented with 15\% heat-inactivated foetal calf serum, $10^{3}$ units $/ \mathrm{ml}$ leukaemia inhibitory factor (Merck), $0.1 \mathrm{mM} \beta$-mercaptoethanol, non-essential amino acids, L-glutamine and penicillin/streptomycin. Cells were maintained in $37^{\circ} \mathrm{C}$ incubator under $5 \% \mathrm{CO}_{2}$. Human B143, HEK293, GM847 and U2OS cells were cultured in Dulbecco's modified Eagle's medium supplemented with $10 \%$ heat-inactivated foetal calf serum and penicillin/ streptomycin.

Generation of knockout and mutant ES cell lines. The $\mathrm{H} 3.3^{\mathrm{G} 34 \mathrm{R}}$ and $A t r x^{-/ Y} \mathrm{ES}$ cell lines were generated in our previous studies ${ }^{30,31}$. CRISPR-Cas9 mediated Atrx, Tp53, Tert and $K d m 4 b$ knockouts were carried out using specific guide RNA (gRNA) (Supplementary Table S2). All positive targeted ES cell lines were identified by PCR analyses using specific primer sets (Supplementary Table 2), followed by confirmation either by reverse transcription-qPCR or Western blot analysis.

Targeted deletion of Atrx exon 17 using Atrx RNA guide \#1 and \#2 was screened by identification of a truncation of a $1850 \mathrm{bp}$ PCR product amplified with Atrx ex17 For and Rev primers.

Targeted deletion of Tp53 exon 4 using Tp53 RNA guide \#1 and \#2 was identified by a reduction of a 340 bp PCR product amplified with Tp53 ex4 For and Rev primers.

Targeted deletion of Tert exon 2 using Tert RNA guide \#1 and \#2 was identified by a truncation of a $1048 \mathrm{bp}$ PCR product amplified with Tert ex2 g2F and g1R primers.

Targeted deletion of Tert exon 2 using Tert RNA guide \#4 and \#5 was identified by a reduction of a $1252 \mathrm{bp}$ PCR product amplified with Tert ex $2 \mathrm{~g} 4 \mathrm{~F}$ and g5R primers.

Targeted deletion of $K d m 4 b$ exon 3 and 5 using $K d m 4 b$ RNA guides \# 1 and \#2 was identified by a loss of a 503 bp PCR product amplified using Kdm $4 \mathrm{~b}$ ex $3 \mathrm{~F}$ and $3 \mathrm{R}$ primers.

IDH1 ${ }^{\mathrm{R} 132 \mathrm{H}}$ mutation was introduced by transfecting Idh1 ex 3 guide 1 (targeting exon 3 of Idh1) together with a repair DNA template carrying a R132H substitution (Supplementary Table S2). Positive mutant lines were screened by PCR amplification of a $604 \mathrm{bp}$ PCR product with Idh1 ex3 For and Rev primers, followed by restriction digest with EcoRI to generate 423 and 181 bp fragments.

Doubling time calculation. In brief, $10^{5}$ cells were plated on a $60 \mathrm{~mm}$ dish; after 28 hours, the cells were counted. The population doubling time or the time required for a culture to double in number is calculated with the following formula: $\mathrm{DT}=\mathrm{T} \ln 2 / \ln (\mathrm{Xe} / \mathrm{Xb})$

$T$ is the incubation time in any units.

$\mathrm{Xb}$ is the cell number at the beginning of the incubation time.

$\mathrm{Xe}$ is the cell number at the end of the incubation time.

Antibodies. Antibodies used were directed against anti-H3 (Abcam, \#ab1791), anti-H3.3 (Abcam, \#ab176840), anti-H3K9me3 (Abcam, ab8898), anti-H3K36me3 (Abcam, \#ab9050), anti- $\gamma$ H2A.X/phospho-histone H2A.X (Ser139) clone JBW301 (Merck Millipore, \#05-636), anti-ATRX (Santa Cruz Biotechnologies, \#sc15408), anti- KDM4B (Abcam, \#ab191434) anti-IDH1 (Sigma Aldrich, SAB4100064), antiIDH1 ${ }^{\mathrm{R} 132 \mathrm{H}}$ (Sigma Aldrich, SAB4200548), anti-HP1a (Merck Millipore, \#MAB3584), anti-PML (Merck Millipore, \#MAB3738), anti-TP53 (Cell Signaling Technologies, \#cst-2524), anti-Flag (Sigma, \#F1804), anti-TERF1 (Alpha Diagnostics, \#TRF12-S) and anti-BrdU (Abcam, \#ab6326), Anti- $\beta$ Actin (AC-15) (Santa Cruz Biotechnology, \#sc69879), Goat anti Rabbit IgG, HRP conjugate (Merck Millipore, \#AP187P), Donkey anti-Mouse IgG HRP conjugate (Merck Millipore, \#AP192P), Donkey anti-Mouse IgG $(\mathrm{H}+\mathrm{L}$ ) Alexa Fluor 594 (Invitrogen, \#A21203), Donkey anti-Rabbit IgG (H + L) Alexa Fluor 488 (Invitrogen, \#A-21206).

Immunofluorescence. Cells were treated with KaryoMAX Colcemid at a final concentration of $10 \mu \mathrm{g} / \mathrm{ml}$ for $1 \mathrm{~h}$ prior to harvest. Cells were subjected to hypotonic treatment in $0.075 \mathrm{M} \mathrm{KCl}$ (room temperature for $5 \mathrm{~min}$ ), cytospun onto slides, and incubated in ice-cold KCM buffer $(120 \mathrm{mM} \mathrm{KCl}, 10 \mathrm{mM}$ Tris- $\mathrm{HCl} \mathrm{pH}$ $7.5,20 \mathrm{mM} \mathrm{NaCl}, 0.5 \mathrm{mM}$ EDTA, $0.1 \%(\mathrm{v} / \mathrm{v})$ Triton X-100 and protease inhibitor) for $5 \mathrm{~min}$. Slides were incubated in ice-cold KCM extraction buffer (KCM and $0.4 \%$ Triton X-100) for $5 \mathrm{~min}$, followed by an incubation in ice-cold KCM blocking buffer (KCM, 2\% BSA, protease inhibitor and AEBSF) for another 5 min. Slides were incubated in the relevant primary (diluted in $1 / 250$ to 500 ) and secondary antibodies (diluted in 1/1200) for $1 \mathrm{~h}$ at $37^{\circ} \mathrm{C}$ in KCM block buffer. After each antibody incubation, slides were washed three times with ice-cold KCM. After washing, they were fixed in $4 \%(\mathrm{v} / \mathrm{v})$ formaldehyde (in KCM) and mounted with DAPI in Vectashield media. Images were collected using a Zeiss imager M2 fluorescence microscope with 100X objective linked to an AxioCam MRm CCD camera system. Images were collected using Zeiss Zen Imaging Software. To determine the percentages of co-localised TERF1/PML, TERF1/HP1 $\alpha$ or TERF1/ $\gamma \mathrm{H} 2 \mathrm{AX}$ foci, at least $1200-1500$ telomeric foci were counted over three independent experiments for each cell line. Percentages of co-localised TERF1/PML, TERF1/HP1 $\alpha$ or TERF1 $/ \mathrm{H} 2 \mathrm{AX}$ foci represent percentages of telomeric foci that show co-staining of PML, HP1 $\alpha$ or $\gamma \mathrm{H} 2 \mathrm{AX}$ over the total number of telomeric foci counted in respective experiments.

Fluorescence in-situ hybridisation (FISH). Cells were treated with Colcemid (KaryoMAX) at a final concentration of $10 \mu \mathrm{g} / \mathrm{ml}$ for $1 \mathrm{~h}$ at $37^{\circ} \mathrm{C}$ prior to harvesting. Cells were subjected to hypotonic treatment in $0.075 \mathrm{M} \mathrm{KCl}$, fixed in methanol: acetic acid (3:1 ratio), and pelleted for $5 \mathrm{~min}$ at $900 \mathrm{~g}$. The cells were washed with fixative two more times, followed by centrifugation prior to each wash The fixed cells were dropped onto slides, then dehydrated sequentially in a $75 \%$, $85 \%$, and $100 \%$ ethanol series at room temperature for 5 min each. Slides were rehydrated in $1 \times$ phosphate buffer saline (PBS) $(137 \mathrm{mM} \mathrm{NaCl}, 5.4 \mathrm{mM} \mathrm{KCl}$, $10 \mathrm{mM} \mathrm{Na}_{2} \mathrm{HPO}_{4}$, and $5 \mathrm{mM} \mathrm{NaH}_{2} \mathrm{PO}_{4} \mathrm{H}_{2} \mathrm{O}$ ) at room temperature for $5 \mathrm{~min}$ and incubated with $0.2 \mu \mathrm{g} / \mathrm{ml} \mathrm{RNase} \mathrm{A}$ in $1 \times \mathrm{PBS}$ for $30 \mathrm{~min}$ at $37^{\circ} \mathrm{C}$. Slides were washed once in $1 \times$ PBS, fixed in $4 \%$ PFA (in PBS), washed again in $1 \times$ PBS, and lastly ethanol dehydrated for $5 \mathrm{~min}$ each. FISH was performed by hybridisation with telomeric and centromeric DNA probes (PNA bio) in hybridisation buffer (20 mM Tris- $\mathrm{HCl} \mathrm{pH} \mathrm{7.5,} 10 \mathrm{mM} \mathrm{NaHPO}_{4} \mathrm{pH} 7.4,10 \mathrm{mM} \mathrm{NaCl}$, and $50 \%$ formamide) and $30 \mu \mathrm{g}$ salmon sperm DNA (Invitrogen) for $3 \mathrm{~min}$ at $80^{\circ} \mathrm{C}$ and left to incubate overnight at $37^{\circ} \mathrm{C}$. Slides were washed in $2 \times$ SSC at room temperature followed by three rounds of washes at $50^{\circ} \mathrm{C}$ in $0.5 \times$ SSC. Slides were ethanoldehydrated at room temperature for $5 \mathrm{~min}$, left to air dry, and mounted with DAPI in Vectashield mounting media. Images were collected as described above.

CO-FISH. Cells were incubated for $12-14 \mathrm{~h}$ in fresh media (DMEM) containing $\operatorname{BrdU}(10 \mu \mathrm{g} / \mathrm{ml})$ and $\operatorname{BrdC}(3.33 \mu \mathrm{g} / \mathrm{ml})$. An hour before harvesting cells were treated with KaryoMAX Colcemid at a final concentration of $10 \mu \mathrm{g} / \mathrm{ml}$. Cells were subjected to hypotonic treatment in $0.075 \mathrm{M} \mathrm{KCl}$, fixed in methanol: acetic acid (3:1 ratio), and pelleted at $900 \mathrm{~g}$ for $5 \mathrm{~min}$. The cells were washed with fixative two more times, with centrifugation between washes. The fixed cells were dropped onto slides and dehydrated in a $75 \%, 85 \%$, and $100 \%$ ethanol series at room temperature for $5 \mathrm{~min}$ each and left to air dry. Slides were rehydrated in $1 \times \mathrm{PBS}$ at room temperature for $5 \mathrm{~min}$, incubated with $0.2 \mu \mathrm{g} / \mathrm{ml} \mathrm{RNase} \mathrm{A} \mathrm{(in} \mathrm{PBS)} \mathrm{at} 37^{\circ} \mathrm{C}$ for $30 \mathrm{~min}$, and stained with $0.5 \mu \mathrm{g} / \mathrm{ml}$ Hoechst 33258 dye (in $2 \times$ saline sodium citrate (SSC: $150 \mathrm{mM} \mathrm{NaCl}, 15 \mathrm{mM}$ sodium citrate, $\mathrm{pH}$ 7) at room temperature for $15 \mathrm{~min}$ (in the dark). Slides were subsequently placed into a shallow tray, covered with $2 \times$ SSC, and exposed to $365 \mathrm{~nm}$ ultraviolet light for $45 \mathrm{~min}$. The BrdU/C incorporated strands were digested with at least $10 \mathrm{U} / \mu \mathrm{l}$ Exonuclease III at room temperature for $1 \mathrm{~h}$. Slides were washed in $1 \times$ PBS, dehydrated in an ethanol series, and left to air dry. FISH was performed by hybridisation with a TAACCC and TTAGGG telomere peptide nucleic acid probe in hybridisation buffer $(20 \mathrm{mM}$ Tris- $\mathrm{HCl} \mathrm{pH} \mathrm{7.5}$ $10 \mathrm{mM}$ NaHPO4, $\mathrm{pH} 7.4,10 \mathrm{mM} \mathrm{NaCl}$ and $50 \%$ formamide) and $30 \mu \mathrm{g}$ salmon sperm DNA (Invitrogen) overnight at $37^{\circ} \mathrm{C}$ (non-denaturing). Slides were washed in $2 \times \mathrm{SSC}$ at room temperature followed by three rounds of washes at $50^{\circ} \mathrm{C}$ in $0.5 \times$ SSC. Slides were ethanol-dehydrated at room temperature for $5 \mathrm{~min}$, left to air dry, and mounted with DAPI in Vectashield mounting media. Images were collected as described above.

Real time-qPCR analysis of gene expression. RNA was prepared using High Pure RNA Isolation kit according to the manufacturer's protocol (Roche). cDNA was synthesised using the cDNA Reverse Transcriptase kit (Life Technologies). The expression levels of target genes were quantitated by qPCR with FastStart Essential DNA Green Master (Roche) using the LightCycler and analysed with LightCycler 96 Software (Roche Life Science). As an internal control, primers specific for Gapdh were used in real-time PCR analysis. The comparative cycle threshold method was used for data analyses and relative fold difference was expressed as 2 $-\Delta \Delta \mathrm{CT}$.

Chromatin immunoprecipitation (ChIP). Cells were harvested and crosslinked with $1 \%$ paraformaldehyde for $10 \mathrm{~min}$ at room temperature. For ATRX and KDM4B ChIP, cells were cross-linked first with 2 mM EGS (Pierce 26103) for $45 \mathrm{~min}$ then with $1 \%$ paraformaldehyde for $20 \mathrm{~min}$. Excess formaldehyde was quenched with glycine at a final concentration of $0.25 \mathrm{M}$. Cell were washed with PBS, pelleted and lysed in cold cell lysis buffer ( $10 \mathrm{mM}$ Tris pH $8,10 \mathrm{mM} \mathrm{NaCl}$, $0.2 \%$ NP40 and protease inhibitors). Nuclei were centrifuged and resuspended in $50 \mathrm{mM}$ Tris $\mathrm{pH} 8,10 \mathrm{mM}$ EDTA and $1 \%$ sodium dodecyl sulphate (SDS), and sonicated with a Bioruptor (Diagenode) to obtain chromatin fragments of $500 \mathrm{bp}$ or less. Resulted chromatin was diluted in IP dilution buffer $(20 \mathrm{mM}$ Tris $\mathrm{pH} 8$, $2 \mathrm{mM}$ EDTA, $150 \mathrm{mM} \mathrm{NaCl}, 1 \%$ Triton X-100 and $0.01 \%$ SDS and protease inhibitors) and pre-cleared with Protein A Agarose beads at $4{ }^{\circ} \mathrm{C}$. Pre-cleared 
chromatin was immunoprecipitated with antibody-bound beads at $4{ }^{\circ} \mathrm{C}$ overnight. For each ChIP reaction, 2-5 $\mu$ g of antibody and $30 \mu \mathrm{l}$ of Protein A Agarose beads (50\% slurry) were used. The immunoprecipitated material was washed and eluted in $100 \mathrm{mM} \mathrm{NaHCO}$ and $1 \%$ SDS. The eluted material was treated with RNaseA, Proteinase $\mathrm{K}$ and $\mathrm{NaCl}$, and reverse-crosslinked at $65^{\circ} \mathrm{C}$ overnight. $10 \mu \mathrm{g}$ tRNA and equal volume Tris-EDTA buffer were added and DNA was phenol/chloroform extracted, followed by precipitation using tRNA and glycogen as carriers $(5 \mu \mathrm{g})$. Purified ChIP DNA was used as template for qPCR using the primers corresponding to telomeric repeats (Telomere Forward and Reverse) and Gapdh promoter (Gapdh Pro For and Rev).

ChIP-seq data. Fastq files of KDM4A $\mathrm{A}^{34}, \mathrm{KDM}_{4} \mathrm{~B}^{33}$ and KDM44 $\mathrm{C}^{33} \mathrm{ChIP}$-seq and matched input samples were aligned to a repeat database with Repeat Enrichment Estimator v1.062. In brief, a repeat assembly file was generated using the Repbase database and reads were aligned to this library and counted. Further details are available in reference ${ }^{62}$. Reads which aligned to telomeres (annotated as (CCCTTA) $\mathrm{n}$ in the mouse repeats database) are shown after normalising for total read counts.

BrdU ChIP. Cells were treated with $10 \mu \mathrm{g} / \mathrm{mL}$ BrdU (Sigma) overnight before harvesting. Genomic DNA was extracted by Qiagen DNeasy kit. gDNA was then sheared into $100-300 \mathrm{bp}$ fragments using a probe sonicator. $10 \mu \mathrm{g}$ of sheared gDNA was denatured for $10 \mathrm{~min}$ at $95^{\circ} \mathrm{C}$ and cooled on ice. Denatured gDNA was incubated with $2 \mu \mathrm{g}$ anti-IgG (Sigma) or anti-BrdU (Abcam, ab6326) antibody diluted in immunoprecipitation buffer $(0.0625 \%$ (v/v) Triton X-100 in PBS), followed by constant rotation overnight at $4{ }^{\circ} \mathrm{C}$. The next day, samples were incubated with $30 \mu \mathrm{l}$ Protein $\mathrm{G}$ magnetic beads (Pierce) for $2 \mathrm{~h}$ rotating at $4{ }^{\circ} \mathrm{C}$. Beads were subsequently washed three times with immunoprecipitation buffer and once with TE buffer. Beads were then incubated twice in elution buffer (1\% (w/v) SDS in $1 \times$ TE buffer) for $15 \mathrm{~min}$ at $65^{\circ} \mathrm{C}$. DNA was precipitated from pooled eluates, along with $10 \%$ inputs, with $300 \mathrm{mM}$ Sodium Acetate (pH 5.2) and Ethanol. Immunoprecipitated DNA was quantified by qPCR using Telomere primers. A standard curve was plotted by serial dilution of Input DNA.

qPCR analysis of telomere Length. Genomic DNA was prepared from mouse ES cell lines for real-time quantitative PCR analysis of telomere length ${ }^{63,64}$ using the LightCycler and analysed with LightCycler ${ }^{\circ} 480$ Software. The average telomere length was measured by quantifying telomeric DNA relative to a single-copy gene. $36 \mathrm{~B} 4$ was used as the single-copy reference gene. $2 \mathrm{ng}$ of genomic DNA, $300 \mathrm{nM}$ primers, and DNA SYBR Green PCR Master mix (Roche) were used for the qPCR reactions. For telomere DNA amplification, the PCR cycling parameters used were $95^{\circ} \mathrm{C}$ for $10 \mathrm{~min}, 30 \mathrm{cycles}$ of $95^{\circ} \mathrm{C}$ for $15 \mathrm{sec}$ and a $56^{\circ} \mathrm{C}$ anneal-extension step for $1 \mathrm{~min}$. For 36B4 DNA amplification, the PCR cycling parameters used were $95^{\circ} \mathrm{C}$ for $10 \mathrm{~min}, 35$ cycles of $95^{\circ} \mathrm{C}$ for $15 \mathrm{~s}, 52^{\circ} \mathrm{C}$ annealing for $20 \mathrm{~s}$ and $72^{\circ} \mathrm{C}$ extension for $30 \mathrm{~s}$. A standard curve was set up for each primer set using wildtype genomic DNA template over a range of $0.8 \mathrm{ng}$ to $100 \mathrm{ng}$. Relative telomere length was represented by the value of telomere divided by the value of $36 \mathrm{~B} 4$ gene.

Telomeric C-circle/qPCR assay. Telomeric C-circle was detected using an assay previously described by Lau et al. $2013^{65}$. Rolling circle amplification of C-circle was performed with $40 \mathrm{ng}$ of genomic DNA, $0.2 \mu \mathrm{g} / \mu \mathrm{L}$ BSA, $0.1 \%$ Tween, $4 \mathrm{mM}$ DTT, $1.2 \mathrm{mM}$ each of dATP, dCTP, dGTP, dTTP and $\varphi 29$ DNA polymerase $(\varphi 29$; $3.75 \mathrm{U} / 16 \mathrm{ng}$ DNA) (NEB) in $1 \times \varphi 29$ buffer). The reaction was incubated at $30^{\circ} \mathrm{C}$ for $8 \mathrm{~h}$ then at $70^{\circ} \mathrm{C}$ for $20 \mathrm{~min}$. For each sample, the assay was performed with and without $\varphi 29$. The assay products were diluted for $\mathrm{qPCR}$ analyses using telomeric DNA and single-copy gene primer (36B4) to determine the level by measuring the increase in total telomeric DNA. C-circle level was reported as the relative telomeric content of the C-circle assay products relative to a single-copy gene (36B4).

Reporting summary. Further information on research design is available in the Nature Research Reporting Summary linked to this article.

\section{Data availability}

The data that support this study are available from the corresponding author upon reasonable request. Source data are provided with this paper.

Received: 11 June 2020; Accepted: 16 March 2021;

Published online: 10 May 2021

\section{References}

1. Palm, W. \& de Lange, T. How shelterin protects mammalian telomeres. Annu. Rev. Genet. 42, 301-334 (2008).

2. de Lange, T. Shelterin: the protein complex that shapes and safeguards human telomeres. Genes Dev. 19, 2100-2110 (2005).
3. Wright, W. E., Piatyszek, M. A., Rainey, W. E., Byrd, W. \& Shay, J. W. Telomerase activity in human germline and embryonic tissues and cells. Dev. Genet. 18, 173-179 (1996).

4. Bryan, T. M. \& Reddel, R. R. Telomere dynamics and telomerase activity in in vitro immortalised human cells. Eur. J. Cancer 33, 767-773 (1997).

5. Yeager, T. R. et al. Telomerase-negative immortalized human cells contain a novel type of promyelocytic leukemia (PML) body. Cancer Res. 59, 4175-4179 (1999)

6. Schwartzentruber, J. et al. Driver mutations in histone H3.3 and chromatin remodelling genes in paediatric glioblastoma. Nature 482, 226-231 (2012).

7. Heaphy, C. M. et al. Altered telomeres in tumors with ATRX and DAXX mutations. Science 333, 425 (2011).

8. Jiao, Y. et al. DAXX/ATRX, MEN1, and mTOR pathway genes are frequently altered in pancreatic neuroendocrine tumors. Science 331, 1199-1203 (2011)

9. Lovejoy, C. A. et al. Loss of ATRX, genome instability, and an altered DNA damage response are hallmarks of the alternative lengthening of telomeres pathway. PLoS Genet. 8, e1002772 (2012).

10. Heaphy, C. M. et al. Prevalence of the alternative lengthening of telomeres telomere maintenance mechanism in human cancer subtypes. Am. J. Pathol. 179, 1608-1615 (2011).

11. Sturm, D. et al. Hotspot mutations in H3F3A and IDH1 define distinct epigenetic and biological subgroups of glioblastoma. Cancer Cell 22, 425-437 (2012).

12. Henson, J. D., Neumann, A. A., Yeager, T. R. \& Reddel, R. R. Alternative lengthening of telomeres in mammalian cells. Oncogene 21, 598-610 (2002)

13. Zhong, Z. H. et al. Disruption of telomere maintenance by depletion of the MRE11/RAD50/NBS1 complex in cells that use alternative lengthening of telomeres. J. Biol. Chem. 282, 29314-29322 (2007).

14. Draskovic, I. et al. Probing PML body function in ALT cells reveals spatiotemporal requirements for telomere recombination. Proc. Natl Acad. Sci. USA 106, 15726-15731 (2009).

15. Fasching, C. L., Bower, K. \& Reddel, R. R. Telomerase-independent telomere length maintenance in the absence of alternative lengthening of telomeresassociated promyelocytic leukemia bodies. Cancer Res. 65, 2722-2729 (2005).

16. Wong, L. H. et al. ATRX interacts with $\mathrm{H} 3.3$ in maintaining telomere structural integrity in pluripotent embryonic stem cells. Genome Res. 20, 351-360 (2010)

17. Wong, L. H. et al. Histone H3.3 incorporation provides a unique and functionally essential telomeric chromatin in embryonic stem cells. Genome Res. 19, 404-414 (2009).

18. Lewis, P. W., Elsaesser, S. J., Noh, K. M., Stadler, S. C. \& Allis, C. D. Daxx is an H3.3-specific histone chaperone and cooperates with ATRX in replicationindependent chromatin assembly at telomeres. Proc. Natl Acad. Sci. USA 107, 14075-14080 (2010).

19. Law, M. J. et al. ATR-X syndrome protein targets tandem repeats and influences allele-specific expression in a size-dependent manner. Cell 143, 367-378 (2010).

20. Udugama, M. et al. Histone variant H3.3 provides the heterochromatic $\mathrm{H} 3$ lysine 9 tri-methylation mark at telomeres. Nucleic Acids Res. 43, 10227-10237 (2015).

21. Voon, H. P. J., Collas, P. \& Wong, L. H. Compromised telomeric heterochromatin promotes Alternative Lengthening Of Telomeres. Trends Cancer 2, 114-116 (2016).

22. Tagami, H., Ray-Gallet, D., Almouzni, G. \& Nakatani, Y. Histone H3.1 and H3.3 complexes mediate nucleosome assembly pathways dependent or independent of DNA synthesis. Cell 116, 51-61 (2004).

23. Napier, C. E. et al. ATRX represses alternative lengthening of telomeres. Oncotarget 6, 16543-16558 (2015).

24. $\mathrm{Wu}, \mathrm{G}$. et al. Somatic histone $\mathrm{H} 3$ alterations in pediatric diffuse intrinsic pontine gliomas and non-brainstem glioblastomas. Nat. Genet. 44, 251-253 (2012).

25. Jiao, Y. et al. Frequent ATRX, CIC, FUBP1 and IDH1 mutations refine the classification of malignant gliomas. Oncotarget 3, 709-722 (2012)

26. Liu, X. Y. et al. Frequent ATRX mutations and loss of expression in adult diffuse astrocytic tumors carrying IDH1/IDH2 and TP53 mutations. Acta Neuropathol. 124, 615-625 (2012).

27. Gao, J. et al. Integrative analysis of complex cancer genomics and clinical profiles using the cBioPortal. Sci. Signal 6, pll (2013).

28. Cerami, E. et al. The cBio cancer genomics portal: an open platform for exploring multidimensional cancer genomics data. Cancer Discov. 2, 401-404 (2012).

29. Henson, J. D. et al. DNA C-circles are specific and quantifiable markers of alternative-lengthening-of-telomeres activity. Nat. Biotechnol. 27, 1181-1185 (2009).

30. Voon, H. P. J. et al. Inhibition of a K9/K36 demethylase by an H3.3 point mutation found in paediatric glioblastoma. Nat. Commun. 9, 3142 (2018).

31. Udugama, M. et al. Ribosomal DNA copy loss and repeat instability in ATRX mutated cancers. Proc. Natl Acad. Sci. USA 115, 4737-4742 (2018). 
32. Berry, W. L. \& Janknecht, R. KDM4/JMJD2 histone demethylases: epigenetic regulators in cancer cells. Cancer Res. 73, 2936-2942 (2013).

33. Das, P. P. et al. Distinct and combinatorial functions of Jmjd2b/Kdm $4 \mathrm{~b}$ and $\mathrm{Jmjd} 2 \mathrm{c} / \mathrm{Kdm} 4 \mathrm{c}$ in mouse embryonic stem cell identity. Mol. Cell 53, 32-48 (2014).

34. Pedersen, M. T. et al. Continual removal of H3K9 promoter methylation by Jmjd2 demethylases is vital for ESC self-renewal and early development. EMBO J. 35, 1550-1564 (2016).

35. Klose, R. J. et al. The transcriptional repressor JHDM3A demethylates trimethyl histone H3 lysine 9 and lysine 36. Nature 442, 312-316 (2006).

36. Black, J. C. et al. Conserved antagonism between JMJD2A/KDM4A and HP1gamma during cell cycle progression. Mol. Cell 40, 736-748 (2010).

37. Huh, M. S. et al. Compromised genomic integrity impedes muscle growth after Atrx inactivation. J. Clin. Investig. 122, 4412-4423 (2012).

38. Banani, S. F. et al. Compositional control of phase-separated. Cell. Bodies. Cell 166, 651-663 (2016).

39. Delbarre, E. et al. PML protein organizes heterochromatin domains where it regulates histone H3.3 deposition by ATRX/DAXX. Genome Res. 27, 913-921 (2017).

40. Luciani, J. J. et al. PML nuclear bodies are highly organised DNA-protein structures with a function in heterochromatin remodelling at the G2 phase. J. Cell Sci. 119, 2518-2531 (2006).

41. Chang, F. T. et al. PML bodies provide an important platform for the maintenance of telomeric chromatin integrity in embryonic stem cells. Nucleic Acids Res. 41, 4447-4458 (2013).

42. Larson, A. G. et al. Liquid droplet formation by HP1alpha suggests a role for phase separation in heterochromatin. Nature 547, 236-240 (2017).

43. Strom, A. R. et al. Phase separation drives heterochromatin domain formation. Nature 547, 241-245 (2017).

44. Bannister, A. J. et al. Selective recognition of methylated lysine 9 on histone H3 by the HP1 chromo domain. Nature 410, 120-124 (2001).

45. Gauchier, M. et al. SETDB1-dependent heterochromatin stimulates alternative lengthening of telomeres. Sci. Adv. 5, eaav3673 (2019).

46. Conomos, D., Reddel, R. R. \& Pickett, H. A. NuRD-ZNF827 recruitment to telomeres creates a molecular scaffold for homologous recombination. Nat. Struct. Mol. Biol. 21, 760-770 (2014).

47. Jiang, W. Q. et al. Induction of alternative lengthening of telomeres-associated PML bodies by $\mathrm{p} 53 / \mathrm{p} 21$ requires HP1 proteins. J. Cell Biol. 185, 797-810 (2009).

48. $\mathrm{Xu}, \mathrm{W}$. et al. Oncometabolite 2-hydroxyglutarate is a competitive inhibitor of alpha-ketoglutarate-dependent dioxygenases. Cancer Cell 19, 17-30 (2011).

49. Osterwald, S. et al. PML induces compaction, TRF2 depletion and DNA damage signaling at telomeres and promotes their alternative lengthening. $J$. Cell Sci. 128, 1887-1900 (2015).

50. Loe, T. K. et al. Telomere length heterogeneity in ALT cells is maintained by PML-dependent localization of the BTR complex to telomeres. Genes Dev. 34, 650-662 (2020).

51. Zhang, $H$. et al. Nuclear body phase separation drives telomere clustering in ALT cancer cells. Mol. Biol. Cell 31, 2048-2056 (2020).

52. Min, J., Wright, W. E. \& Shay, J. W. Clustered telomeres in phase-separated nuclear condensates engage mitotic DNA synthesis through BLM and RAD52. Genes Dev. 33, 814-827 (2019).

53. Perrem, K., Colgin, L. M., Neumann, A. A., Yeager, T. R. \& Reddel, R. R. Coexistence of alternative lengthening of telomeres and telomerase in hTERTtransfected GM847 cells. Mol. Cell Biol. 21, 3862-3875 (2001).

54. $\mathrm{Hu}$, J. et al. Antitelomerase therapy provokes ALT and mitochondrial adaptive mechanisms in cancer. Cell 148, 651-663 (2012).

55. Masutomi, K. et al. The telomerase reverse transcriptase regulates chromatin state and DNA damage responses. Proc. Natl Acad. Sci. USA 102, 8222-8227 (2005).

56. Chan, S. W. \& Blackburn, E. H. Telomerase and ATM/Tellp protect telomeres from nonhomologous end joining. Mol. Cell 11, 1379-1387 (2003).

57. Fishbein, L. et al. Whole-exome sequencing identifies somatic ATRX mutations in pheochromocytomas and paragangliomas. Nat. Commun. 6, 6140 (2015).
58. Job, S. et al. Telomerase activation and ATRX mutations are independent risk factors for metastatic pheochromocytoma and paraganglioma. Clin. Cancer Res. 25, 760-770 (2019)

59. Kaelin, W. G. Jr. \& McKnight, S. L. Influence of metabolism on epigenetics and disease. Cell 153, 56-69 (2013).

60. Hakin-Smith, V. et al. Alternative lengthening of telomeres and survival in patients with glioblastoma multiforme. Lancet 361, 836-838 (2003).

61. Pekmezci, M. et al. Adult infiltrating gliomas with WHO 2016 integrated diagnosis: additional prognostic roles of ATRX and TERT. Acta Neuropathol. 133, 1001-1016 (2017).

62. Day, D. S., Luquette, L. J., Park, P. J. \& Kharchenko, P. V. Estimating enrichment of repetitive elements from high-throughput sequence data. Genome Biol. 11, R69 (2010).

63. Cawthon, R. M. Telomere measurement by quantitative PCR. Nucleic Acids Res. 30, e47 (2002).

64. Callicott, R. J. \& Womack, J. E. Real-time PCR assay for measurement of mouse telomeres. Comp. Med. 56, 17-22 (2006).

65. Lau, L. M. et al. Detection of alternative lengthening of telomeres by telomere quantitative PCR. Nucleic Acids Res. 41, e34 (2013).

\section{Acknowledgements}

This work was supported by Worldwide Cancer Research, The Brain Tumour Charity, Cure Brain Cancer Foundation Australia and American Brain Tumor Association.

\section{Author contributions}

M.U., L.H., A.G., M.C., B.V., F.-L.C., J.R.M., H.P.V. and L.H.W. performed the experiments and analysed the data. P.P.D and P.C. provided materials and contributed to discussion. M.U., L.H., A.G., J.R.M, P.C., H.P.V. and L.H.W. wrote and edited the manuscript.

\section{Competing interests}

The authors declare no competing interests.

\section{Additional information}

Supplementary information The online version contains supplementary material available at https://doi.org/10.1038/s41467-021-22543-z.

Correspondence and requests for materials should be addressed to H.P.J.V. or L.H.W.

Peer review information Nature Communications thanks Vincent Geli and the other, anonymous, reviewer(s) for their contribution to the peer review of this work.

Reprints and permission information is available at http://www.nature.com/reprints

Publisher's note Springer Nature remains neutral with regard to jurisdictional claims in published maps and institutional affiliations.

Open Access This article is licensed under a Creative Commons Attribution 4.0 International License, which permits use, sharing, adaptation, distribution and reproduction in any medium or format, as long as you give appropriate credit to the original author(s) and the source, provide a link to the Creative Commons license, and indicate if changes were made. The images or other third party material in this article are included in the article's Creative Commons license, unless indicated otherwise in a credit line to the material. If material is not included in the article's Creative Commons license and your intended use is not permitted by statutory regulation or exceeds the permitted use, you will need to obtain permission directly from the copyright holder. To view a copy of this license, visit http://creativecommons.org/ licenses/by/4.0/.

(C) The Author(s) 2021 